\title{
A Non-Stationary and Probabilistic Approach for Drought Characterization Using Trivariate and Pairwise Copula Construction (PCC) Model
}

Soumyashree Dixit ( $\nabla$ dixitsoumya27@gmail.com )

National Institute of Technology Warangal https://orcid.org/0000-0002-4929-0155

K V Jayakumar

NIT Warangal: National Institute of Technology Warangal

\section{Research Article}

Keywords: NSPI, NRDI, MEI, IOD, SST, SOI, PCC

Posted Date: June 1st, 2021

DOl: https://doi.org/10.21203/rs.3.rs-382218/v1

License: (c) (1) This work is licensed under a Creative Commons Attribution 4.0 International License.

Read Full License

Version of Record: A version of this preprint was published at Water Resources Management on February 11th, 2022. See the published version at https://doi.org/10.1007/s11269-022-03069-5. 


\title{
A Non-stationary and Probabilistic Approach for Drought Characterization using Trivariate and Pairwise Copula Construction (PCC) Model
}

\author{
Soumyashree Dixit ${ }^{1}$ and K V Jayakumar ${ }^{2}$ \\ ${ }^{1}$ Research Scholar, Department of Civil Engineering, dixitsoumya27@gmail.com \\ Professor of Civil Engineering, kvj@nitw.ac.in \\ National Institute of Technology Warangal, India
}

\begin{abstract}
Under the variable climatic conditions, the conventional Standardized Precipitation Index (SPI) and Reconnaissance Drought Index (RDI) are inadequate for predicting extreme drought characteristics. So in the present study, two indices namely, Non-stationary Standardized Precipitation Index (NSPI) and Non-stationary Reconnaissance Drought Index (NRDI) are developed by fitting non-stationary gamma (for precipitation series) and lognormal (for initial values, $\left.\delta_{0}\right)$ distributions. The Generalized Additive Model in Location, Scale and Shape (GAMLSS) framework, with time varying location parameters considering the external covariates, is used to fit the non-stationary distributions. This includes various large scale climate indices namely Multivariate ENSO Index (MEI), Southern Oscillation Index (SOI), Sea Surface Temperature (SST), and Indian Ocean Dipole (IOD) as external covariates for the non-stationary drought assessment. The performances of stationary and non-stationary models are compared based on the Akaika Information Criterion (AIC). Additionally, the drought characteristics are evaluated using Run theory analysis for both stationary and non-stationary drought indices. The study also concentrated on the trivariate copula as well as the Pairwise Copula Construction (PCC) models to estimate the drought recurrence intervals. The comparison of two copula models revealed that the PCC model performed better than the trivariate Student's $t$ copula model. The recurrence intervals arrived at for the drought events are different for trivariate copula model and PCC model. The area taken for the study is the Upper and Lower sub basins of the Godavari River basin. This study shows that non-stationary drought indices will be helpful in the accurate estimate of the drought characteristics under the changing climatic scenario.
\end{abstract}

Key Words: NSPI, NRDI, MEI, IOD, SST, SOI, PCC 


\subsection{Introduction}

Drought is defined as the abnormally prolonged dry weather condition that results in hydrological imbalance for a particular area and duration. Irrespective of the shortage in the availability of water, it is one of the challenging issues which human society is confronting. Drought has been classified as agricultural drought, meteorological drought and hydrologic drought depending on its dependence on the qualitative and quantitative role of precipitation, evapotranspiration (ET) and runoff in monitoring the drought characteristics. Another classification is the socio-economic drought that takes into account the reduction in the water supply (Mishra and Singh, 2010). The water scarcity factors are high water demand and consumption, irregular distribution of rainfall and high temperature. Unplanned use of water can create detrimental effects on agriculture, environment and socio-economic status of a region which can cause extreme drought events.

Indian agronomy and cropping pattern are very much dependent on the onset and withdrawal of the monsoon, the distribution of rainfall and the total water storage capacities of reservoirs. Irregularities in monsoons such as late onset, long breaks and early withdrawal of water, make Indian agriculture more vulnerable to droughts of different durations and magnitudes (Prabhakar and Shaw, 2008). A study by Dutta et al. (2015) showed that more than $68 \%$ of the population in India is dependent upon agriculture, about $16 \%$ of the total area is drought-prone and annually around 50 million people are severely affected by the drought. The drought during the year 2014-15 caused severe inadequacy of water by affecting around 330 million people (Mishra et al. 2016). These studies give a clear indication that the adequate attention must be paid to the drought assessment of the Indian River basins that are prone to droughts.

The drought monitoring for a particular area can be handled through various indices. Many authors have developed univariate drought indices, viz., Soil Moisture Deficit Index, 
SMDI (Narasimhan and Srinivasan, 2005), Standardized Precipitation Index, SPI (McKee et al. 1993), Crop Moisture Index, CMI (Palmer 1968), Surface Water Supply Index, SWSI (Shafer et al. 1982), Standardized Runoff Index, SRI (Shukla and Wood, 2008), and Soil Moisture Drought Index, SMDI (Welford et al. 1993). In addition to these, various studies have concentrated on the multivariate drought indices such as the Joint Deficit Index, JDI, (Kao and Govindaraju, 2010), Standardized Precipitation Evapotranspiration Index, SPEI, (VicenteSerrano et al., 2010), Aggregated Drought Index, ADI (Keyantash and Dracup, 2004), and Multivariate Standardized Drought Index, MSDI (Hao and AghaKouchak, 2013). The World Meteorological Organization (WMO) recognised that the SPI is the most frequently used index for drought assessment (Svoboda et al. 2002). SPI is solely based on precipitation and gives information on meteorological drought. The core strength of SPI is that it can be computed for different timescales which allows for monitoring both the short and long term drought situations. Although it is the most preferred index for estimation of meteorological drought, it does not consider the evapotranspiration demand. In a country like India, both precipitation and evapotranspiration play a major role in the determination of drought events. Reconnaissance Drought Index (RDI) was introduced by Tsakiris and Vangelis (2005) that considered both precipitation and evapotranspiration and can overcome the limitations of SPI. So in this study both SPI and RDI are taken for identification of drought status.

It is well known that the Stationarity is the basic assumption in the statistical interpretations of time series in hydrologic processes. Stationarity refers to the parameters of the climate that are invariant and free of trends (Wang et al. 2015). Stationary property is questionable in the context of global warming and anthropogenic changes in climate. The stationary Gamma distribution is fitted to the precipitation time series for the estimation of SPI whereas stationary Log-normal distribution is fitted for estimation of RDI. The outcome of environmental changes exhibits non-stationary behaviour in climatic parameters and hence 
indicators have been developed for identifying drought status in non-stationary conditions which can deal with better aspects of water management. The Standardized Non-stationary Precipitation Index (SnsPI) is developed by Russo et al. (2013) and further used by Wang et al. (2015). This index deals with the time varying mean which is the extension of the stationary SPI. The large scale climate indices based on El Niño Southern Oscillation (ENSO) events cannot be neglected in the computation of nonstationary SPI and RDI (Bazrafshan and Hejabi, 2018) because the Indian summer monsoon and its hydro-meteorology are influenced by the global scale climate indices. Past studies have demonstrated that the variability in regional hydrology and extreme events like droughts and floods are connected with the global scale climatic phenomenon (Kahya and Dracup, 1993). Some of the studies have proved the linkage between the global climate indices and the Indian climatic conditions. The variability in the Indian Ocean is strongly related to ENSO events (Krishnamurthy and Kirtman, 2003). NorthEast India exhibits a significant correlation with Pacific decadal variability and SSTs (Mayers et al. 2015). Sahai et al. (2003) identified that the SST oscillations and Indian Summer Monsoon Rainfall (ISMR) have significant correlation among each other. The influence of ENSO on the north Indian precipitation, temperature and potential evapotranspiration (PET) observed during the monsoon season was identified by Tamaddun et al. (2019). The spatial and seasonal changes of rainfall over the Ganges and Brahmaputra basins based on the ENSO events and Indian Ocean Dipole (IOD) modes were investigated by (Pervez and Henebry, 2014). The major drought events in different parts of the world are influenced by ENSO events (Trenberth et al. 2014). It can be, hence, summarised that covariates provide greater insight into the factors of climate that influence the distribution of climatic parameters over time.

The analysis of drought properties plays a satisfactory role in monitoring the negative impacts on water resources and agriculture (Oguntunde et al. 2017). Drought characteristics like severity, duration and peak must have a dependence structure and hence a multivariate 
analysis of drought is widely accepted in hydro-meteorological studies for better understanding of drought risk assessment, drought return period and for detecting the drought warning criteria. A multivariate distribution function named as copula can join the marginal distributions by conserving the dependence structure of drought characteristics. Copulas are widely used for capturing the association between two or more random variables (Salvadori and De Michele, 2004; Grimaldi and Serinaldi, 2006; Genest and Favre, 2007, Zhang et al., 2015). Studies have shown that copulas have tremendous application in hydrology. The joint probability between peak discharge, duration and volume (Gr"aler et al., 2013), drought severity and duration (Das et al. 2020), association between drought characteristics (Ganguli and Reddy, 2012), and Multivariate Drought Index (MVDI) that combined the margins of precipitation and soil moisture (Hao and AghaKouchak, 2013) are some of the examples of the use of copula. Multivariate flood quantiles were estimated by Salvadori et al. (2011) considering the joint distribution of annual maximum flood peak, volume and initial water levels of the dam. The meta-elliptical copulas were applied to flood variables for the analysis of the return period at Romaine River in Québec Genest et al. (2007).

Several past studies indicated that the vine copula model is more flexible in handling the higher dimension copulas by extending the bivariate copula to higher dimensions (Aas et al. 2009). The basic idea of vine copulas is to construct high dimensional copulas based on a stage-wise mixing of bivariate copulas by decomposing the full density function into a product of low-dimensional density functions. The higher dimensional multivariate Student's t copula is not effective enough to model the complexity in the dependence structure of extreme event variables. Because of this limitation of higher dimensional copulas, an efficient way of copula construction method was introduced for a highly dependent structure to model the complex pattern called vine or pair-copula (Bedford and Cooke, 2001; Aas et al. 2009). Many studies have been conducted in the past to define the vital role of pair copula model in hydrological 
analysis. A trivariate discharge modelling considering flood duration, peak and severity was conducted by Song and Kang (2011) using pair-copula construction. A vine copula model was constructed to analyse the flood frequency using variables like peak discharge, duration and volume Gräler et al. (2013). Daneshkhah et al. (2016) developed a multivariate pair copula model by using the flood properties in River Beas of the Himalayan region indicating that the Himalayan Rivers are highly affected by the monsoon fluctuations and stored snow cover.

The article by Milly et al. (2008) showed that the stationarity hypothesis is no longer relevant and hence it should not be applicable to hydro-meteorology studies. So the present study considered a non-stationary concept of drought estimation and analysis including reliable climate oscillations. Non-stationary drought modelling of SPI and RDI in the river basin scale in India has not been previously carried out. GAMLSS package in R developed by Rigby and Stasinopoulos (2005) is used in the current study for the non-stationary modelling of SPI and RDI in the Godavari River basin. Many studies have been carried out in the past for the nonstationary drought frequency analysis (Osorio and Galiano, 2012; Wang et al. 2015; Rashid et al. 2019) as well as the non-stationary flood frequency analysis (Villarini et al. 2009, Lopez and Frances, 2013; Debele et al. 2017) using GAMLSS model. Das et al. (2020) studied the impact of large scale oscillations on drought characteristics using the GAMLSS model in the Himalayan states of Sikkim and Uttarakhand. A proper study focused on non-stationary drought analysis and risk assessment in the Godavari River basin has not been carried out. Most of the area in the river basin has severe impacts on the economical, agricultural and social factors due to flood and drought events. The construction of dependence among drought characteristics (severity, duration and peak) is studied by using the trivariate Student's t copula and PCC models. Further the return period analysis is carried out for a better understanding of the statistical behaviour of drought events. The awareness regarding the extreme events and 
their response in river basin scale with the changing climate will be useful in planning, managing and combating the impacts on water resources systems.

\subsection{Study area and Data Description}

In this study, two sub basins (Upper and Lower) of the Godavari River basin have selected for non-stationary assessment of drought. Godavari is the second largest river basin in India and flows through the states of Maharashtra, Telangana, Andhra Pradesh, Odisha, Chhattisgarh and some parts of Karnataka, Madhya Pradesh. The total area of the Godavari basin is about $3,12,810$ sq. $\mathrm{km}$., which is $10 \%$ of the total area of the country. The length and width are about $995 \mathrm{~km}$ and $583 \mathrm{~km}$ respectively. It has many tributaries joining it from the right and left side with Pranhita being the largest tributary, covering $34.87 \%$ of the total drainage area. The basin has a tropical climate and as a whole receives on an average $85 \%$ of the annual rainfall during the Southwest monsoon. The annual precipitation in the river basin varies from 600 to $1200 \mathrm{~mm}$. Most part of the river basin is rain-fed and the distribution of rainfall is highly irregular. The average temperature in the basin varies from $15^{\circ} \mathrm{C}$ in the winter to $45^{\circ} \mathrm{C}$ in the peak of summer. High variability in temperature and precipitation in the river basin affects the evapotranspiration and relative humidity of the basin. Therefore, it is essential to estimate the non-stationary drought condition related to precipitation and evapotranspiration variability, which will be helpful in obtaining an accurate form of drought properties.

In the present study, the Indian Meteorology Department (IMD) daily precipitation datasets of resolution $0.25 \times 0.25$ for the period of 1950 to 2017 are used in the development of the Non-stationary Standardised Precipitation Index (NSPI). The Non-stationary Reconnaissance Drought Index (NRDI) requires both precipitation and evapotranspiration data to estimate the meteorological drought. Hence, the monthly $0.5 \times 0.5$ resolution evapotranspiration data has been downloaded from the Climate Research Unit (CRU) 4.03TS data sites for the same period (Zarch et al. 2015, Lawal et al. 2019, Harris et al. 2020). Then 
the data is extracted and regridded to the IMD grids. There is an effect of large scale global climate indices on a non-stationarity evaluation of drought phenomenon. So in this study, NSPI and NRDI were computed based on the association with four global scale climate indices namely Indian Ocean Dipole (IOD), Southern Oscillation Index (SOI), Sea Surface Temperature (SST) and Multivariate ENSO Index (MEI). ENSO and IOD affect the Indian summer monsoon (Pokhrel et al. 2012). The Nino 3.4 (5N-5S, 170W-120W) anomalies are represented based on the average SST across the Pacific Ocean and can be acquired from https://www.esrl.noaa.gov/psd/data/correlation/nina34.data. The difference in monthly time series of MSL between Tahiti and Darwin is measured in terms of the SOI which has a strong influence on Indian summer monsoon (Bhalme and Jadhav, 1984) and can be downloaded from http://www.bom.gov.au/climate/current/soihtm1.shtml. During the ENSO events, MEI captures a more realistic image of the coupled oceanic-atmospheric anomalies in the tropical pacific. It is based on the combination of five variables: $\mathrm{U}$ (zonal) and $\mathrm{V}$ (meridional) components of surface wind, (P) Sea Pressure Levels, SST and OLR (outgoing long wave radiation). MEI can be obtained from the site, https://www.esrl.noaa.gov/psd/enso/mei.ext/table.ext.html. In the Indian Ocean, a coupled ocean-atmospheric phenomenon is represented as IOD (Saji et al., 1999) and measured in terms of DMI. DMI is termed as SST anomaly difference between the Western $\left(50^{\circ} \mathrm{E}-70^{\circ} \mathrm{E}\right.$ and $\left.10^{\circ} \mathrm{S}-10^{\circ} \mathrm{N}\right)$ and South-Eastern $\left(90^{\circ} \mathrm{E}-110^{\circ} \mathrm{E}\right.$ and $\left.10^{\circ} \mathrm{S}-0^{\circ} \mathrm{N}\right)$ and can be downloaded from (http://www.jamstec.go.jp/frsgc/research/d1/iod/iod/dipole_mode_index.html.

\subsection{Methodology}

Initially, the $0.25 \times 0.25$ gridded IMD daily precipitation data is converted to monthly scale for the Lower and Upper Godavari basin over 68 years (1950-2017). For same period, the monthly evapotranspiration data is downloaded from the Climate Research Unit (CRU) 4.03 TS data site and regridded to IMD grids. For these study areas, the cumulative 
precipitation and evapotranspiration are calculated using 3-, 6- and 12-month moving average methods for the above written period. The aggregated global scale monthly climate indices are calculated using the 3-, 6- and 12- month moving average method. Then the lag value from 0 to 12 are computed for each of the four large scale climate indices.

\subsection{Non-stationary Reconnaissance Drought Index (NRDI) and Non-stationary Standardized Precipitation Index (NSPI) Development}

The stationary RDI is calculated based on the assumption that the parameters related to initial values $\left(\delta_{0}\right)$ are constant with time (Tsakiris and Vangelis, 2005). Under non-stationarity condition, some parameters of the distribution function of $\delta_{0}$ can get changed. The initial value $\delta_{0}$ is taken as the ratio of precipitation series to evapotranspiration series in different time windows (3-, 6- and 12-month), that can be computed using the Eq. 1.

$$
\delta_{0}(t)=\frac{\sum_{j=1}^{n} P_{j}(t)}{\sum_{j=1}^{n} \operatorname{PET}_{j}(t)}
$$

Further, for the computation of NSPI and NRDI, the correlation analysis between the precipitation and global scale climate indices as well as the computed $\delta_{0}$ values (3-,6- and 12 month) and the global scale climate indices of different lags (1-12) are performed using Kendall's method (Kendall, 1955) at a significance level of 0.05 . The significant covariates from potential large scale climate indices are evaluated from the best lags based on the minimum p-value. Further, the NSPI and NRDI can be developed using the filtered covariates by fitting the GAMLSS model.

\subsection{GAMLSS Model Development}

GAMLSS package used in this study was developed by Rigby and Stasinopoulos (2005). This model has been widely accepted to obtain the non-stationary parameters related to its parametric distribution varying linearly and nonlinearly with respect to the significant covariates. In the present study, the random variable $y_{i}$ (precipitation series and the ratio 
between aggregated precipitation and evapotranspiration series) was assumed to have a parametric cumulative distribution function. The related time varying parameters can be modelled as a function of selected covariates viz. are the climate indices namely SST, SOI, MEI and IOD by using the GAMLSS model. The step by step details on the use of GAMLSS analysis is available in Rigby and Stasinopoulos (2005) and Stasinopoulos and Rigby (2007). The independent observations $y_{j}$, with $j=1, \ldots, n$ have distribution function $f\left(y_{j}, \theta_{i}\right)$ where $\theta_{i}=$ $\theta_{1}^{\mathrm{i}} \ldots . \theta_{\mathrm{q}}^{\mathrm{i}}$ vector of $\mathrm{q}$ distribution parameters which denote the location, scale and shape. The distribution parameters are related to the monotonic link functions denoted by $\mathrm{g}_{\mathrm{k}}($.$) , where k=$ $1, \ldots, \mathrm{q}$, which creates a relationship between covariates and random variables using a semiparametric additive model and outlined in Eq. 2.

$$
\mathrm{g}_{\mathrm{k}}\left(\theta_{\mathrm{k}}\right)=\mathrm{x}_{\mathrm{k}} \Psi_{\mathrm{k}}+\sum_{\mathrm{j}=1}^{\mathrm{J}} \mathrm{h}_{\mathrm{jk}}\left(\mathrm{x}_{\mathrm{jk}}\right)
$$

Here, $x_{k}$ is a matrix that represents the explanatory variables of order $n \times j_{k}$ (length of the covariate vectors $), \theta_{\mathrm{k}}\left(\theta_{1 \mathrm{k}}, \ldots \ldots, \theta_{\mathrm{jk}}\right)$ are the vectors of parameters of length $\mathrm{j}_{\mathrm{k}}$, and $\mathrm{h}_{\mathrm{jk}}($.$) is$ an additive function that is flexible in modelling the dependence of the parameters of the response variable with relation to the explanatory variables $\mathrm{x}_{\mathrm{j}_{\mathrm{k}}}$. Flexibility in modelling the dependence parameters on the covariates can be achieved using the linear or smoothing form of variation. The selected covariates based on the Kendall's $\tau$ lag correlation method for different time windows (3-, 6- and 12 - months) of precipitation as well as the series of initial values $\left(\delta_{0}\right)$ are varied linearly to the parameters ( here $\mu_{\mathrm{t}}$ is chosen as a time varying parameter) of the distribution.

In the present work, for computing the NSPI for the drought status of a particular location, a two parametric Gamma distribution is fitted to the precipitation series with linearly varying location and constant scale parameter ensuring a relationship between precipitation series and selected explanatory variables as shown in Eq. 5, using Eq.3 and 4

$$
\mathrm{y}_{\mathrm{t}} \sim \operatorname{Gamma}\left(\mu_{\mathrm{t}}, \sigma\right)
$$




$$
\mu_{t}=a_{o}+a_{1} I_{1}(t)+a_{2} I_{2}(t)+\cdots+a_{n} I_{n}(t)
$$

Where $a_{0}, \ldots \ldots, a_{n}$ are estimated mean coefficients for the linear variability for a particular location after fitting non-stationary Gamma distribution and $\mathrm{I}_{1}, \ldots \ldots, \mathrm{I}_{\mathrm{n}}$ represent the explanatory climate variables at time t.

$$
\mathrm{f}\left(y_{t}, \mu_{\mathrm{t}}, \sigma\right)=\frac{1}{\left(\sigma^{2} \mu_{\mathrm{t}}\right)^{1 / \sigma^{2}}} \frac{\mathrm{y}^{\frac{1}{\sigma^{2}}-1} \mathrm{e}^{-\mathrm{y} /\left(\sigma^{2} \mu_{\mathrm{t}}\right)}}{\left(1 / \sigma^{2}\right)}
$$

The cumulative distribution functions of the aggregated rainfall series (3-, 6- and 12month) were computed by fitting the non-stationary model and then transformed into standard normal values using Eq. 6.

$$
\mathrm{NSPI}=\varphi^{-1}\left(\mathrm{f}\left(y_{t}, \mu_{\mathrm{t}}, \sigma\right)\right)
$$

Where $f\left(y_{t}, \mu_{t}, \sigma\right)$ are the CDFs of the aggregated precipitation series, $y_{t}$, is the aggregated precipitation at any time $\mathrm{t}$, and $\varphi^{-1}$ is the inverse $\mathrm{CDF}$ values.

Additionally, non-stationary lognormal distribution with linearly varying location parameter $\left(\mu_{t}\right)$ with time considering the respective covariates and with the constant scale parameter $(\sigma)$, is fitted to the $\delta_{0}$ values as shown in Eq. 7 and Eq. 8.

$$
\begin{gathered}
\mathrm{y}_{\mathrm{t}} \sim \operatorname{LogNormal}\left(\mu_{\mathrm{t}}, \sigma\right) \\
\mu_{\mathrm{t}}=\mathrm{b}_{\mathrm{o}}+\mathrm{b}_{1} \mathrm{I}_{1}(\mathrm{t})+\mathrm{b}_{2} \mathrm{I}_{2}(\mathrm{t})+\cdots+\mathrm{b}_{\mathrm{n}} \mathrm{I}_{\mathrm{n}}(\mathrm{t})
\end{gathered}
$$

Where $b_{0}, \ldots \ldots, b_{n}$ are estimated mean coefficients for the linear variability for a particular location for the fitted non-stationary $\log$ normal distribution and $\mathrm{I}_{1}, \ldots \ldots, \mathrm{I}_{\mathrm{n}}$ are the explanatory climate variables at time t.

Then using the time variant location parameter and the invariant scale parameter, the NRDI is estimated using the Eq. 9.

$$
\operatorname{NRDI}(\mathrm{t})=\frac{\mathrm{y}_{\mathrm{t}}-\mu_{\mathrm{t}}}{\sigma}
$$


Here, $y_{t}=\ln \left(\delta_{0}\right) ; \mu_{\mathrm{t}}$ is the time varying arithmetic mean and $\sigma$ is the standard deviation of the observational variable.

In this work, the parameters for lognormal and Gamma distribution are estimated by Rigby and Stasinopoulos (RS) algorithm in the GAMLSS framework. The distribution function $\mathrm{f}\left(\mathrm{y}_{\mathrm{j}}, \theta_{\mathrm{i}}\right)$ is selected based on the largest maximum-likelihood value. Generally, the quality of fitting is not justified by the maximum likelihood. Besides maximum likelihood, the selection of both the models (stationary and non-stationary) is evaluated in terms of lowest AIC values.

In NSPI and NRDI, the dry periods are represented as negative values while the wet conditions are shown as positive values. The classification of NSPI and NRDI is similar to the standard SPI (Mckee et al., 1993) and RDI (Tsakiris, 2007).

\subsection{Multivariate Drought Frequency Analysis}

The drought characteristics can be identified using the Run theory analysis, which is also widely used in the drought frequency analysis (Mishra et al., 2009, Ganguli and Reddy, 2012). A run is defined as the values below a preferred truncation level by considering the positive and negative run (Yevjevich, 1967). In the present study, a value of -0.8 is considered as the threshold value below which all the values are taken as drought events. This study considered three drought characteristics namely drought duration (D), peak (P) and severity (S). The drought duration is referred to as the intervals between the onset and offset of drought for a particular threshold level. The drought peak can be computed as the absolute lowest index value reached by the drought time series throughout the period of a run. A simple arithmetic sum of NSPI and NRDI deficit for each month under a certain drought duration can be defined as the drought severity ( $\mathrm{S}_{\mathrm{NSPI}}$ and $\left.\mathrm{S}_{\mathrm{NRDI}}\right)$, as given in Eq. 10 and Eq.11

$$
\begin{aligned}
& \mathrm{S}_{\mathrm{NSPI}}=-\sum_{\mathrm{t}=1}^{\mathrm{d}} \operatorname{NSPI}_{\mathrm{i}, \mathrm{t}} \mathrm{i}=1, \ldots \ldots, \mathrm{n} \\
& \mathrm{S}_{\mathrm{NRDI}}=-\sum_{\mathrm{t}=1}^{\mathrm{d}} \operatorname{NRDI}_{\mathrm{i}, \mathrm{t}} \mathrm{i}=1, \ldots \ldots, \mathrm{n}
\end{aligned}
$$




\subsection{Multivariate dependence modelling using copula constructions}

Drought is a complex phenomenon in hydro-meteorological studies. Multivariate techniques are flexible in modelling the complex dependence structure between drought characteristics such as peak, duration and severity. The limitations regarding univariate drought frequency analysis can be overcome by the evolution of multivariate drought frequency analysis based on copula analysis. Copulas ensure the construction of joint probability distribution uniquely based on the univariate marginal distribution of parameters (Sklar, 1959). Generally, copula a C combines the univariate distribution to a multivariate distribution, with a uniformly distributed margins varying in the range of $u(0,1)$. The joint distribution function $\mathrm{F}\left(\mathrm{y}_{1} \ldots \ldots . \mathrm{y}_{\mathrm{n}}\right)$ is shown in Eq. 12.

$$
\mathrm{F}\left(\mathrm{y}_{1}, \ldots \ldots ., \mathrm{y}_{\mathrm{n}}\right)=\mathrm{C}\left(\mathrm{u}_{1}, \ldots \ldots . . \mathrm{u}_{\mathrm{n}}, \theta\right)
$$

Where $\mathrm{C}$ is the copula distribution function, associated with the copula parameter $\theta . F_{1}, \ldots \ldots, F_{n}$ are the marginal distribution of random variables $\left(\mathrm{y}_{1}, \ldots \ldots ., \mathrm{y}_{\mathrm{n}}\right)$. The dependence between $\mathrm{y}_{1}, \ldots \ldots ., \mathrm{y}_{\mathrm{n}}$ is characterised entirely by the copula $\mathrm{C}$ that is invariant by monotonically increasing transformations of the margins. The copula function $\mathrm{C}$ is stated a unique function only when the marginal distributions are continuous. The joint probability density function linked with the copula function $\mathrm{C}$ can be presented by Eq. 13

$$
f\left(y_{1}, \ldots \ldots, y_{n}\right)=f_{1}\left(y_{1}\right) \times \ldots \ldots . . \times f_{n}\left(y_{n}\right) \times c\left[F_{1}\left(y_{1}\right), \ldots \ldots \ldots, F_{n}\left(y_{n}\right)\right]
$$

The probability density function $f_{1}\left(y_{1}\right), \ldots . . f_{n}\left(y_{n}\right)$ of the dependent variables are linked to the density function c as expressed in Eq. 14.

$$
c\left(u_{1}, \ldots \ldots, u_{n}\right)=\partial^{n} C\left(u_{1}, \ldots \ldots . u_{n}\right) /\left(\partial u_{1} \ldots \ldots \ldots . . \partial u_{n}\right)
$$

Where $\mathrm{u}_{1}=\mathrm{F}_{1}\left(\mathrm{y}_{1}\right), \ldots \ldots \ldots$, and $\mathrm{u}_{\mathrm{n}}=\mathrm{F}_{\mathrm{n}}\left(\mathrm{y}_{\mathrm{n}}\right)$ 
For example a trivariate distribution function, fitted to three dependent drought characteristics $\mathrm{P}, \mathrm{D}$ and $\mathrm{S}$ with marginal CDFs $\mathrm{F}_{\mathrm{P}}, \mathrm{F}_{\mathrm{D}}$ and $\mathrm{F}_{\mathrm{S}}$ can be represented based on copula function that guarantees the existence of a unique function c such that, all $P, D$ and $S, \in$ R. The trivariate joint probability distribution resulting in the parameter associated with the specified copula function is presented by Eq. 15 .

$$
f(P, D, S)=f_{P}(P) \times f_{D}(D) \times f_{S}(S) \times c\left[F_{P}(P), F_{D}(D), F_{S}(S)\right]
$$

Different types of copula families, namely Frank, Gaussian, Gumbel, Clayton, and Student's t copula are used in many hydro-meteorological studies. The dependency status between the interrelated drought variables is represented by the respective copula parameter. In this study, the parameters of copula families are estimated using the maximum likelihood estimation method based on its fitted marginal distribution. The best fitted copula is estimated based on the Goodness of Fit (GoF) measures namely Kolmogorov-Smirnov test (KS), Cramervon Misses (CVM), and Chi-square (Chsq) tests as suggested by Genest and Fever (2007). AIC criteria and the maximum likelihood function are also used to justify the best fitted copula model. The copula parameters and their constructions carried out presented briefly in this study and for more details regarding copula, Nelsen (2006) may be referred.

Various copulas are represented in Eq. 16 to Eq. 20

Clayton: $\mathrm{C}_{\theta}(\alpha, \beta)=\left(\alpha^{-\theta}+\beta^{-\theta}-1\right)^{-\theta}$ for all $\theta(0, \infty)$

Frank: $\quad C_{\theta}(\alpha, \beta)=-\frac{1}{\theta} \log \left(1+\frac{(\exp (-\theta \alpha)-1)(\exp (-\theta \beta)-1)}{\exp (-\theta)-1}\right)$ for $\theta \in R\{0\}$

Gaussian: $C_{\theta}(\alpha, \beta)=\int_{-\infty}^{\varphi^{-1(\alpha)}} \int_{-\infty}^{\varphi^{-1(\beta)}} \frac{1}{2 \pi \sqrt{1-\theta^{2}}} \mathrm{e}^{\frac{2 \theta u v-u^{2}-v^{2}}{2\left(1-\theta^{2}\right)}} d u d v$

Gumbel: $C_{\theta}(\alpha, \beta)=\exp \left\{-\left[-(-\log \alpha)^{\theta}+(-\log \beta)^{\theta}\right]^{1 / \theta}\right\}$, for $\theta \in[1, \infty)$

Student-t: $\mathrm{C}_{\theta}(\alpha, \beta)=\int_{-\infty}^{\mathrm{T}_{\gamma}{ }^{-1(\alpha)}} \int_{-\infty}^{\mathrm{T}_{\gamma}{ }^{-1(\beta)}} \frac{\Gamma\left(\frac{v+2}{2}\right)}{\Gamma\left(\frac{v}{2}\right) v \pi \sqrt{1-\theta^{2}}}\left\{1+\frac{\mathrm{u}^{2}+\mathrm{v}^{2}-2 \theta \mathrm{uv}}{v\left(1-\theta^{2}\right)}\right\} \mathrm{dudv}$ 
Brechmann and Schepsmeier, (2013) observed that the exchangeable Archimedean copula including multivariate Student's t copula and Normal copulas are not flexible enough to develop an accurate model dependent status among a larger number of variables. When the dimension of random variable increases, the construction of a copula becomes difficult.

The probabilistic framework that gives a density of an n-dimensional distribution in terms of a regular vine is given in Bedford and Cooke (2001, 2002). Regular vines are broadly categorised into two subsets i.e. D-vine and Canonical vine (Kurowicka and Cooke, 2006, Aas et al., 2009). Vine is a flexible graphically represented tree-like structure that computes the pairwise construction of variables that are mutually dependent, called as PCC model. In case of the D-vine structure, the node has a link to more than two edges based on the number of random variables and basically, it forms a hierarchical trend structure from $1^{\text {st }}$ to the $\mathrm{n}^{\text {th }}$ node in the tree.

The D-vine structure that is used to model joint probability related to the drought characteristics $P, D$, and $S$ with the given marginal densities $F_{P}, F_{D}, F_{S}$ respectively is demonstrated. Similarly, a multivariate density function can be decomposed using a canonical vine (C-vine) structure. $\mathrm{C}$-vine is a tree-like structure where the main component is uniquely defined as the root node and the other variables are the branch nodes directly connected to the root with $\mathrm{n}-\mathrm{j}$ edges. The $\mathrm{D}$-vine structure can be converted to a $\mathrm{C}$-vine by slightly modifying the structure. Here D-vine structure is selected for the joint density decomposition as shown in Eq. 21

$$
\begin{aligned}
& \mathrm{F}(\mathrm{P}, \mathrm{D}, \mathrm{S})=\mathrm{f}_{\mathrm{P}}(\mathrm{P}) \times \mathrm{f}_{\mathrm{D}}(\mathrm{D}) \times \mathrm{f}_{\mathrm{S}}(\mathrm{S}) \mathrm{c}_{\mathrm{PD}}\left\{\mathrm{F}_{\mathrm{P}}(\mathrm{P}), \mathrm{F}_{\mathrm{D}}(\mathrm{D})\right\} \times \mathrm{c}_{\mathrm{DS}}\left\{\mathrm{F}_{\mathrm{D}}(\mathrm{D}), \mathrm{F}_{\mathrm{S}}(\mathrm{S})\right\} \times \\
& \quad \mathrm{C}_{\mathrm{PS} \mid \mathrm{D}}\left\{\mathrm{F}_{\mathrm{PD}}(\mathrm{P} \mid \mathrm{D}), \mathrm{F}_{\mathrm{SD}}(\mathrm{S} \mid \mathrm{D})\right\} \\
& \mathrm{C}_{\mathrm{PD}}\left\{\mathrm{F}_{\mathrm{P}}(\mathrm{P}), \mathrm{F}_{\mathrm{D}}(\mathrm{D})\right\} \text { represents the bivariate copula fitted between } \mathrm{F}_{\mathrm{P}}(\mathrm{P}) \text { and } \mathrm{F}_{\mathrm{D}}(\mathrm{D}) . \\
& \mathrm{c}_{\mathrm{PS} \mid \mathrm{D}}\left\{\mathrm{F}_{\mathrm{PD}}(\mathrm{P} \mid \mathrm{D}), \mathrm{F}_{\mathrm{SD}}(\mathrm{S} \mid \mathrm{D})\right\} \text { represents the bivariate copula fitted to the second tree variables } \\
& \mathrm{F}_{\mathrm{PD}}(\mathrm{P} \mid \mathrm{D}), \mathrm{F}_{\mathrm{SD}}(\mathrm{S} \mid \mathrm{D}) .
\end{aligned}
$$


In the present study, the Archimedean copulas like Gumbel, Clayton, Frank and the Meta elliptical copulas namely Gaussian and Student's t copulas are used for finding the dependency parameter among the drought variables. Additionally a D-vine pair copula structure is constructed between the drought characteristics by identifying the advantages of pair copula over the multivariate copula that can capture the entire dependency among the variables. Daneshkhah et al. (2016) noted that the dependencies between multivariate data show a complex structure. For example, the parameters of Student's t copula show a single degree of freedom which is the driving force for the dependency of all other pair of variables. Because of this limitation, a unique method of copula construction named as vine copula is introduced. The conventional vine model is compared with the multivariate Student's t copula. The pairwise copula construction method is used in this study to find the copula parameters which further can be used to evaluate the frequency of non-stationary drought indices (NSPI and NRDI).

\subsection{Estimation methods for pair-copula models}

The steps included in this study for pair copula construction are outlined as follows:

Firstly, the dependency measurement between drought characteristics like peak - duration, duration - severity and severity - peak are estimated using Kendall's $\tau$ and Spearman's $\rho$. Then, an appropriate D-vine model is chosen in terms of the dependency of variables. Graphical tools like Kendall plot (K-plot) and Chi-plots are useful for the optimum choice of bivariate copula models that are defined by Genest and Favre (2007). In addition to graphical tools, Schirmacher and Schirmacher (2008) presented various popular analytical tools for the evaluation of the copula models between the dependent variables. The Goodness of Fit (GoF) tests called as the Vuong and Clarke tests, are applied to find the suitable copula family for this study (Vuong, 1989 and Clarke, 2007). Commonly used AIC criteria to discriminate between models are also used in this study to find an optimum solution regarding the selection of copula family. 
After deciding the pairwise copula models, the parameter estimation is conducted using the maximum likelihood estimation method which maximises log-likelihood function. The process of parameter estimation for the three-dimensional distribution function for a vine structure is given in Eq. 22 .

$$
\begin{aligned}
L(P, D, S \mid \theta)= & f_{P}(P) \times f_{D}(D) \times f_{S}(S) \times c_{P D}\left\{F_{P}(P), F_{D}(D) ; \theta_{P D}\right\} \times c_{D S}\left\{F_{D}(D), F_{S}(S) ; \theta_{D S}\right\} \times \\
& c_{P S \mid D}\left\{F_{P D}(P \mid D), F_{S D}(S \mid D) ; \theta_{P S \mid D}\right\}
\end{aligned}
$$

Where $\theta=\left(\theta_{\mathrm{PD}}, \theta_{\mathrm{DS}}, \theta_{\mathrm{PS} \mid \mathrm{D}}\right)$

$\mathrm{l}(\mathrm{P}, \mathrm{D}, \mathrm{S} \mid \theta)=\log \left\{\mathrm{c}_{\mathrm{PD}}\left(\mathrm{F}_{\mathrm{P}}(\mathrm{P}), \mathrm{F}_{\mathrm{D}}(\mathrm{D}) ; \theta_{\mathrm{PD}}\right)\right\}+\log \left\{\mathrm{c}_{\mathrm{DS}}\left(\mathrm{F}_{\mathrm{D}}(\mathrm{D}), \mathrm{F}_{\mathrm{S}}(\mathrm{S}) ; \theta_{\mathrm{DS}}\right)\right\}+$

$$
\log \left\{\mathrm{c}_{\mathrm{PS} \mid \mathrm{D}}\left(\mathrm{F}_{\mathrm{PD}}(\mathrm{P} \mid \mathrm{D}), \mathrm{F}_{\mathrm{SD}}(\mathrm{S} \mid \mathrm{D}) ; \theta_{\mathrm{PS} \mid \mathrm{D}}\right)\right\}
$$

Where $F_{P D}(P \mid D)=h\left(P, D, \theta_{P D}\right)$ and $F_{S D}(S \mid D)=h\left(D, S, \theta_{D S}\right)$

The parameters of the copula function can be estimated by choosing a particular tree structure. The first tree parameters can be estimated from the fitted copula between the pairwise variables in the first tree, then the second tree parameter and so on. The association between the first tree and second tree can be achieved using conditional distribution function also namely h functions which are presented in Eq. 23 and Eq. 24.

$$
\begin{aligned}
& \mathrm{h}\left(\mathrm{P} / \mathrm{D} \mid \theta_{\mathrm{PD}}\right)=\frac{\partial \mathrm{C}_{\mathrm{P}, \mathrm{D}}\left[\left(\mathrm{F}(\mathrm{P}), \mathrm{F}(\mathrm{D}) \mid \theta_{\mathrm{PD}}\right)\right]}{\partial \mathrm{F}(\mathrm{D})} \\
& \mathrm{h}\left(\mathrm{D} / \mathrm{S} \mid \theta_{\mathrm{DS}}\right)=\frac{\partial \mathrm{C}_{\mathrm{D}, \mathrm{S}}\left[\left(\mathrm{F}(D), \mathrm{F}(\mathrm{S}) \mid \theta_{\mathrm{DS}}\right)\right]}{\partial \mathrm{F}(\mathrm{D})}
\end{aligned}
$$

Here, $\partial \mathrm{C}_{\mathrm{P}, \mathrm{D}}$ is the bivariate copula distribution function with parameter $\theta_{\mathrm{PD}}$ specified for peak and duration whereas $\partial C_{D, S}$ is the bivariate copula distribution function with parameter $\theta_{D S}$. The inverse of $\mathrm{h}$ function $\left(\mathrm{h}^{-1}\right)$ gives an inverse conditional distribution function of variables (Brechman and Schepsmeier, 2013).

In this study, the vine copula model is used to obtain the multivariate distribution among drought characteristics and the drought frequency analysis is carried out to identify the 
changes in the return period with respect to the trivariate copula model. The return period can be obtained by selecting the appropriate copula family based on the dependent parameters.

\subsection{Non-stationary SPI and RDI indices}

In this section, non-stationary assessment of SPI and RDI are presented for the Upper and Lower Godavari River basin with 67-years (1951-2017) of data records. SPI and RDI are computed in this study by fitting stationary Gamma and Log-normal distributions to the aggregated precipitation and initial values $\left(\delta_{0}\right)$ series respectively. The global scale climate indices are considered as external covariates for evaluating the NSPI and NRDI. These nonstationary based indices are constructed by using the GAMLSS package in R. The basis for this study to incorporate large scale climate indices is that the global climatology is highly affected by the climatic phenomenon over the Pacific and Indian oceans (Rashid and Beecham, 2019). For the Lower and Upper Godavari River basins, the monthly aggregation (3-, 6- and 12- month moving average) of precipitation and evapotranspiration data are prepared. In addition to that, the moving average (3-, 6- and 12-month) of climate indices are obtained and then organised into 13 different lag values from 0 to 12 . The time-varying parameters are the function of explanatory variables. The location parameter of Gamma distribution and Lognormal distribution is varying linearly with the significant covariates for the required observations, simultaneously keeping the scale parameter constant. The Maximum Likelihood Estimation (MLE) method is used for the evaluation of parameters for Gamma as well as the Log-normal distribution. Comparison between the stationary and non-stationary models is also carried out by estimating the two stationary based indices namely SSPI and SRDI by keeping the parameters invariant with time.

Kendall correlation analysis is carried out at a significance level of 0.05 for the assessment of significant large scale climate indices based on the lag values for different time scales. Table 1 displays the dominant covariates for respective parameters of fitted distributions 
for two optimised non-stationary models for both the sub basins. On analysing the outcomes of lag correlation, it is observed that the 3-month cumulative precipitation and initial values showed a significant correlation with SOI and IOD for the Upper Godavari basin and SOI for the Lower Godavari basin for different lags respectively. Similarly, SOI is identified as the most influential covariate for 6-month aggregated precipitation and initial values series for the Upper Godavari basin whereas SOI and SST showed a quantitative amount of influence in the Lower Godavari basin for different lag values. The MEI, SOI and SST are significantly associated with 12-month cumulative precipitation and aggregated initial values for both the sub basins.

Here, the stationary and non-stationary models are optimised by minimizing the AIC. Table 2 represents the AIC values for non-stationary and stationary models. The AIC values obtained from fitted non-stationary Gamma and Log-normal distributions considering the explanatory variables revealed that the AIC values are continuously lesser than those obtained from the stationary models fitted to precipitation and initial values time series. It can be noted that the non-stationary models achieved better performance than the stationary models. The inclusion of various climate oscillations with preferred lag for estimating the non-stationary models can efficiently detect the climate variability.

Table 1 Significant lag for different large scale climate oscillations for 3-, 6- and 12-month time scales for the Upper and Lower sub basin

\begin{tabular}{|c|c|c|c|c|c|c|c|c|c|}
\hline NRDI & SOI & MEI & IOD & SST & NSPI & SOI & MEI & IOD & SST \\
\hline Upper sub basin & & & & & Upper sub basin & & & & \\
\hline 3-month & 2 & & 0 & & 3-month & 2 & & 5 & \\
\hline 6-month & 2 & & & & 6-month & 2 & & & \\
\hline 12-month & 0 & 0 & & 0 & 12-month & 0 & 0 & & 0 \\
\hline Lower sub basin & & & & & Lower sub basin & & & & \\
\hline 3-month & 4 & & & & 3-month & 4 & & & \\
\hline 6-month & 3 & & & 2 & 6-month & 3 & 2 & & \\
\hline 12-month & 3 & 4 & & 3 & 12-month & 3 & 3 & & 5 \\
\hline
\end{tabular}


Table 2 Comparison between stationary and non-stationary models using AIC values

\begin{tabular}{|c|c|c|c|c|}
\hline Models & NRDI & SRDI & NSPI & SSPI \\
\hline & Upper sub basin & & Upper sub basin & \\
\hline 3-month & 5272 & 5272 & 7119.57 & 7119.145 \\
\hline 6-month & 5615 & 5617 & 7591.586 & 7592.802 \\
\hline 12-month & 3759 & 3828 & 6175.181 & 6231.682 \\
\hline & Lower sub basin & & Lower sub basin & \\
\hline 3-month & 6923 & 6928 & 8935.202 & 8937.593 \\
\hline 6-month & 7268 & 7278 & 9266.781 & 9266.588 \\
\hline 12-month & 5061 & 5115 & 7343.492 & 7380.212 \\
\hline
\end{tabular}

\subsection{Comparison of Historical Drought Characteristics}

The drought events are identified for 3-, 6- and 12-month aggregation level for both stationary and non-stationary models. A dry event is defined considering the index values are on a negative side and with a value lesser than the threshold value of -0.8 . When the index values are continuously positive or more than the value of +0.8 , they are described as wet events.

It was observed from the AIC values that the non-stationary models performed better than stationary models. It can be concluded that the SPI and RDI estimated from the nonstationary models, in combination with the external covariates gave better results than the stationary models. The outputs in the form of rationales are the drought indices (NSPI, SPI, NRDI and RDI) that are transformed from the cumulative probability of rainfall and initial values $\left(\delta_{0}\right)$. There are many differences of signals between the stationary and non-stationary time series, which are due to the inclusion of the external covariates for computation of the non-stationary models. Large dissimilarities of signals are observed between NSPI and SSPI for 3-, 6- and 12-month aggregation levels demonstrated in (Fig.1 and Fig.2) for both the sub basins. Further, the changes are evident between the non-stationary and stationary signals because of the time varying mean which is associated with the external covariates. So the conclusion derived is that the external covariates are important aspects that should not be neglected for the non-stationary drought estimation. These dissimilarities are also apparent in 
case of drought characteristics like peak, duration and severity because a stationary Gamma and Log-normal distributions fitted to the total range of rainfall and initial values to find SPI and RDI are fairly different from the non-stationary models (NSPI and NRDI). The box plots for 3-month (first row), 6-month (second row) and 12-month (third row) time windows are shown in Fig. 3 and Fig. 4 for Upper and Lower Godavari sub basins respectively to identify the variations of the drought characteristics for the comparison of stationary and non-stationary models. In these figures, P1, D1 and S1 refer to non-stationary drought characteristics while P2, D2 and S2 refer to stationary characteristics. After comparing 3-month NSPI and SSPI, significant differences are identified in the drought characteristics in the Lower Godavari sub (Fig 3(b)) basin compared to the Upper Godavari sub basin (Fig 3(a)). Larger differences are evident in the drought severity and peak between NSPI and SSPI for the Lower sub basin for 3-month time scale. In the case of duration, the Upper sub basin showed that there are significant variations between NSPI and SSPI for 3-month time scale whereas the Lower sub basin showed less variations. Fig. 4 show the comparison between NRDI and SRDI for the spatial and temporal variability of drought characteristics for the 3-month time scale. The estimated severities of SRDI series are lower than the severity from NRDI series in the case of Upper sub basin whereas the estimated peaks of SRDI series are higher than those estimated from the NRDI series. In case of the Lower sub basin, the peak and severity estimated from 3month SRDI series are higher than that of the 3-month NRDI series. The comparison between NRDI and SRDI showed some variations in drought duration. From Fig 3 (c), it is observed that the Upper sub basin displayed significant changes in peak, duration and severity of the 6month NSPI and SSPI series. In the Lower sub basin, there are significant variations of peak and severity whereas lesser variations of NSPI and SSPI are detected for the drought duration (Fig. 3(d)). From Fig.4 (c) and (d), no significant variations of the drought characteristics are observed for NRDI and SRDI for both the sub basins for the 6-month time scale. Comparison 
of the non-stationary approach (NSPI and NRDI) and stationary approach (SSPI and SRDI) for the 12-month time scale for the drought events in both sub basins revealed, significant deviations in severity, peak and duration. It can, hence, be concluded that substantial variations of drought characteristics are evident in the case of NSPI and SPPI as well as NRDI and SRDI series for a 12-month time window when compared to 3- and 6-month time windows for both the sub basins.

The differences observed in the drought characteristics between the stationary and nonstationary models have significant role in the implementation of sustainable water resources systems planning and management. The underestimation of drought characteristics leads to deficiency in water storage and supply which affects the irrigation management activities. So the accurate estimation of drought phenomenon and drought characteristics must be made and for this, multivariate drought frequency analysis can be used. In this study, non-stationary models have been taken into consideration for further analysis using trivariate and pairwise copula. 

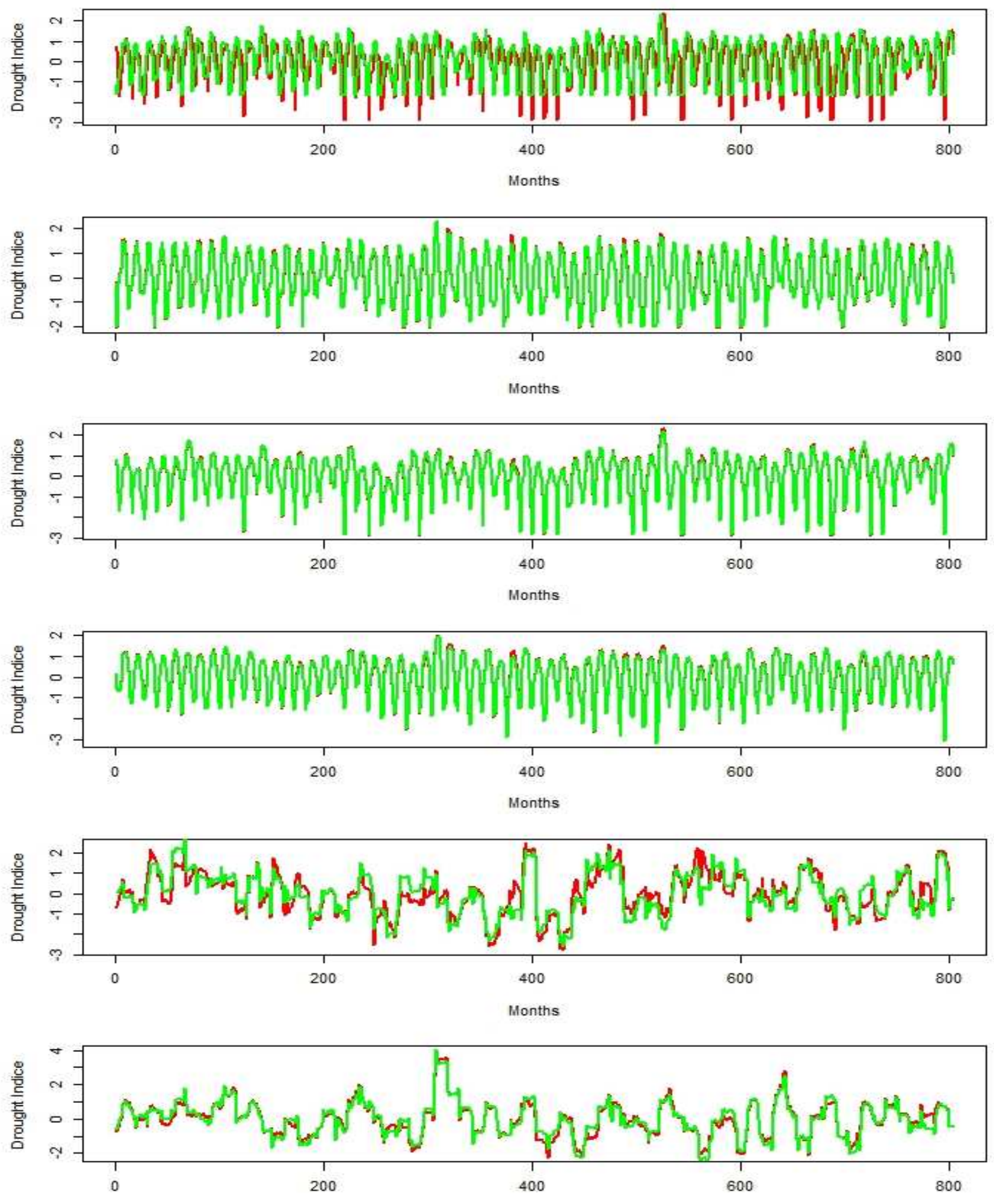

Fig. 1. The NSPI and SSPI drought signals during 1951-2017 for 3-, 6- and 12-month time scales: first time series shows 3-month time scale for Upper Godavari sub basin; second time series shows 3-month time scale for Lower Godavari sub basin; third time series shows 6month time scale for Upper Godavari sub basin; fourth time series shows 6-month time scale for Lower Godavari sub basin; fifth time series shows 12-month time scale for Upper Godavari 
sub basin; sixth time series shows 12-month time scale for Lower Godavari sub basin.
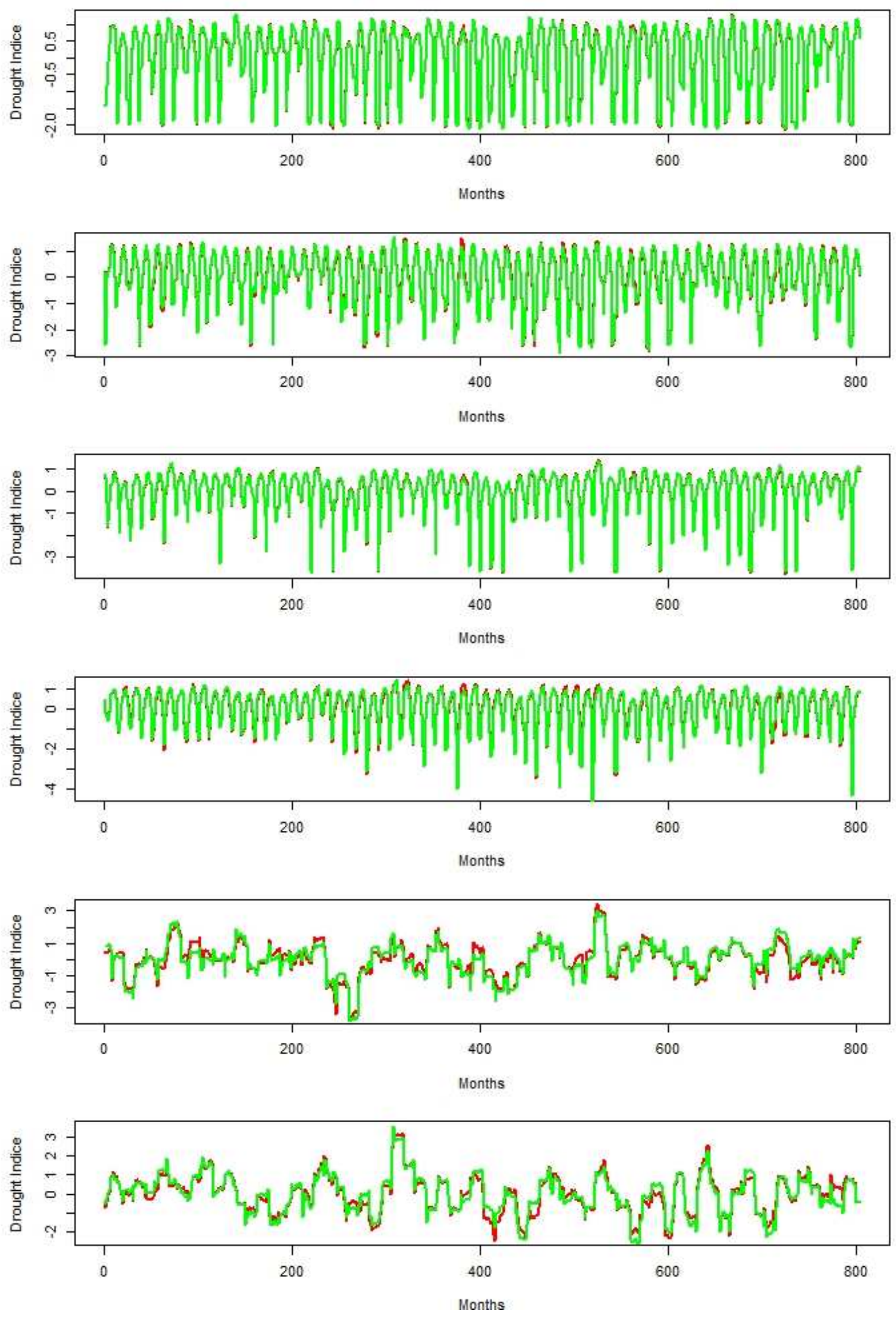
Fig.2. The NRDI and SRDI drought signals during 1951-2017 for 3-, 6- and 12-month time scales: first time series shows 3-month time scale for Upper Godavari sub basin; second time series shows 3-month time scale for Lower Godavari sub basin; third time series shows 6month time scale for Upper Godavari sub basin; fourth time series shows 6-month time scale

for Lower Godavari sub basin; fifth time series shows 12-month time scale for Upper Godavari sub basin; sixth time series shows 12-month time scale for Lower Godavari sub basin
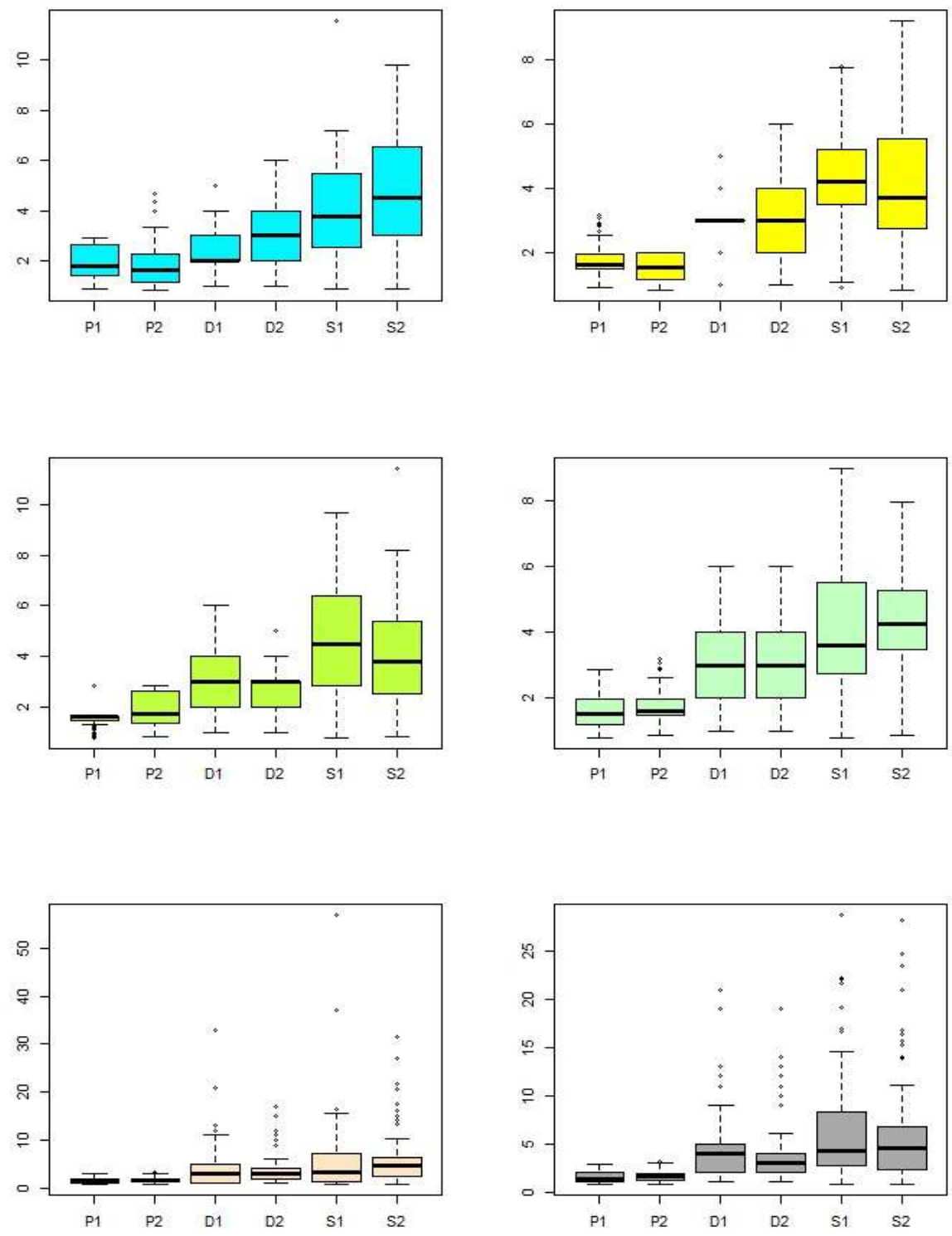

Fig. 3. The comparison using box plots for drought variables (peak, duration and severity) for stationary and non-stationary drought signals: first row shows comparison of drought variables for NSPI and SSPI for 3-month time scale for Upper sub basin and Lower sub basin respectively; Second row show comparison of drought variables for NSPI and SSPI for 6month time scale for Upper sub basin and Lower sub basin respectively; third row show comparison of drought variables for NSPI and SSPI for 12-month time scale for Upper sub basin and Lower sub basin respectively. 

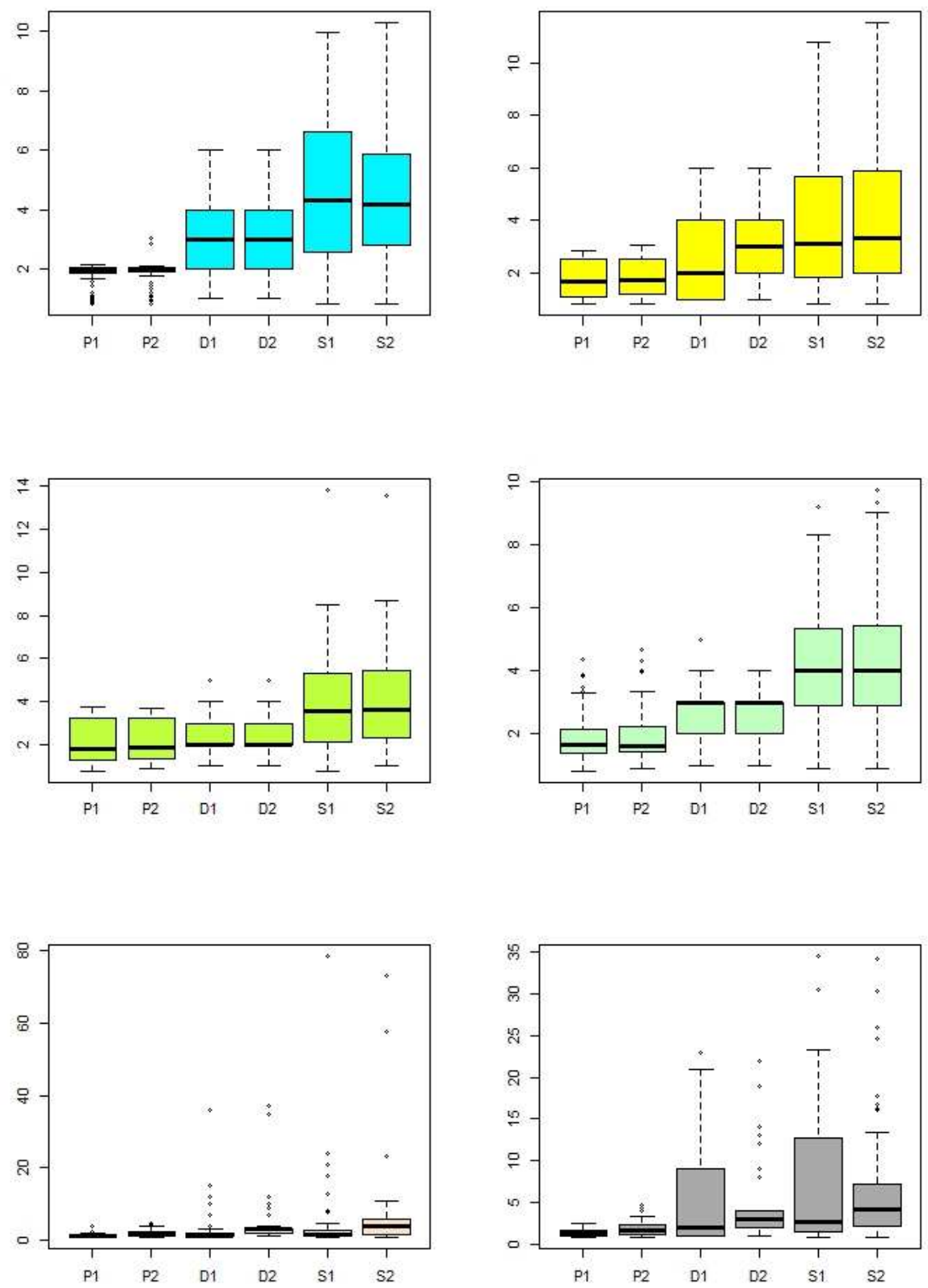

Fig. 4. The comparison using box plots for drought variables (peak, duration and severity) for stationary and non-stationary drought signals: first row shows comparison of drought variables for NRPI and SRDI for 3-month time scale for Upper sub basin and Lower sub basin respectively; Second row show comparison of drought variables for NRDI and SRDI for 6-month time scale for Upper sub basin and Lower sub basin respectively; third row show comparison of drought variables for NRDI and SRDI for 12-month time scale for Upper sub basin and Lower sub basin respectively. 


\subsection{Trivariate Copula Models}

The trivariate copula models are fitted between the estimated peak, duration and severity of the drought for 3-, 6- and 12- month time scales. The Archimedean copulas (Gumbel, Frank and Clayton) and elliptical copulas (Gaussian and Student's t) that are suitable to preserve the multivariate relationship between the characteristics of the have been evaluated in this study. Different types of distributions namely Gumbel, Gamma, Log - normal, Weibull and Exponential distributions were fitted to the drought characteristics. The best fitted distributions for several time scales are obtained based on AIC criteria and the log-likelihood values to find the marginal distributions that can be modelled based on trivariate copula approach for the period of 1951-2017 are provided in supplementary Table S1-Table S6.

The pairwise dependency between variables i.e. peak - duration, duration - severity, severity - peak are studied to justify the association between the drought characteristics. Kendall's $\tau$ and Spearman's $\rho$ rank correlation coefficients are used for detecting the relationship status within the drought characteristics are given in the supplementary document Table S7. Further, the best fitted trivariate copula model among the copulas is decided by analysing the GoF measures - KS, CVM, Chsq considering 2000 sample runs including AIC, log-likelihood values and their estimated parameters are represented in Table 3 and Table 4. The parameter estimation of trivariate copula analysis is conducted using the Maximum Likelihood Estimation (MLE) method. The results in Table 3 and Table 4 show that the Student's t copula performed better rather than the other trivariate copula models.

It can be justified from the results that Student's t copula is an appropriate model to fit a trivariate joint distribution of the drought characteristics. For modelling of different extreme events, the higher dimensional Student's t copula is more popular in hydrological studies (Ganguli and Reddy, 2013). The main limitation of modelling of the higher dimensional Student's t copula is that it has only a single degree of freedom for each pair of parameters 
(Aas et al., 2009). However, this limitation can be further efficiently modified by the PCC models

Table 3 Trivariate Copula analysis for Non-stationary Reconnaissance Drought

Characteristics

\begin{tabular}{|c|c|c|c|c|c|c|c|c|c|c|c|c|c|c|c|}
\hline \multirow[b]{2}{*}{ Upper sub basin } & \multicolumn{5}{|c|}{ 3-month } & \multicolumn{5}{|c|}{ 6-month } & \multicolumn{5}{|c|}{ 12-month } \\
\hline & Gumbel & Clayton & Frank & Normal & $\begin{array}{l}\text { Student's } \\
\text { t copula }\end{array}$ & Gumbel & Clayton & Frank & Normal & $\begin{array}{c}\text { Student's } \\
\text { t copula }\end{array}$ & Gumbel & Clayton & Frank & Normal & $\begin{array}{c}\text { Student's } \\
\text { t copula }\end{array}$ \\
\hline Parameter & 1.9 & 2.0 & 6.2 & 0.7 & 0.7 & 1.9 & 1.5 & 5.3 & 0.7 & 0.7 & 2.9 & 2.6 & 8.3 & 0.8 & 0.7 \\
\hline Loglikelihood & 41.5 & 53.0 & 47.9 & 48.2 & 97.5 & 36.1 & 39.4 & 38.5 & 51.1 & 81.3 & 47.7 & 36.0 & 39.3 & 45.6 & 70.6 \\
\hline AIC & -81.0 & -104.0 & -93.8 & -92.3 & -187 & -70.3 & -76.7 & -74.9 & -98.2 & -154 & -93.4 & -69.9 & -76.6 & -87.1 & -133 \\
\hline KS & 0.2 & 0.0 & 0.2 & 0.5 & 0.4 & 0.3 & 0.1 & 0.2 & 0.4 & 0.3 & 0.2 & 0.1 & 0.2 & 0.3 & 0.8 \\
\hline Chsq & 0.4 & 0.1 & 0.3 & 0.4 & 0.7 & 0.1 & 0.0 & 0.1 & 0.1 & 0.2 & 0.1 & 0.0 & 0.0 & 0.0 & 0.1 \\
\hline CVM & 0.2 & 0.1 & 0.1 & 0.2 & 0.5 & 0.1 & 0.1 & 0.1 & 0.4 & 0.6 & 0.0 & 0.0 & 0.0 & 0.0 & 0.2 \\
\hline \multicolumn{16}{|l|}{ Lower sub basin } \\
\hline Parameter & 2.1 & 1.6 & 6.5 & 0.8 & 0.8 & 1.8 & 1.7 & 5.4 & 0.7 & 0.7 & 2.7 & 1.8 & 8.1 & 0.8 & 0.8 \\
\hline Loglikelihood & 51.4 & 43.9 & 52.0 & 55.1 & 96.3 & 31.9 & 45.0 & 39.5 & 54.9 & 86.9 & 46.5 & 29.1 & 40.1 & 44.1 & 68.7 \\
\hline AIC & -100.8 & -85.7 & -102 & -106.3 & -184 & -61.8 & -87.9 & -77.0 & -105.7 & -165 & -91.1 & -56.1 & -78.1 & -84.2 & -129 \\
\hline KS & 0.2 & 0.0 & 0.2 & 0.5 & 0.1 & 0.4 & 0.1 & 0.4 & 0.5 & 0.8 & 0.3 & 0.2 & 0.3 & 0.0 & 0.0 \\
\hline Chsq & 0.1 & 0.0 & 0.2 & 0.3 & 0.4 & 0.1 & 0.1 & 0.2 & 0.0 & 0.4 & 0.2 & 0.0 & 0.1 & 0.1 & 0.5 \\
\hline CVM & 0.1 & 0.0 & 0.0 & 0.0 & 0.0 & 0.0 & 0.0 & 0.0 & 0.4 & 0.6 & 0.2 & 0.1 & 0.1 & 0.2 & 0.1 \\
\hline
\end{tabular}

Table 4 Trivariate Copula analysis for Non-stationary Standardized Precipitation Drought Characteristics

\begin{tabular}{|c|c|c|c|c|c|c|c|c|c|c|c|c|c|c|c|}
\hline & \multicolumn{5}{|c|}{ 3-month } & \multicolumn{5}{|c|}{ 6-month } & \multicolumn{5}{|c|}{ 12-month } \\
\hline Upper sub basin & Gumbel & Clayton & Frank & Normal & $\begin{array}{c}\text { Student's } \\
\text { t copula }\end{array}$ & Gumbel & Clayton & Frank & Normal & $\begin{array}{c}\text { Student's } \\
\text { t copula }\end{array}$ & Gumbel & Clayton & Frank & Normal & $\begin{array}{c}\text { Student's } \\
\text { t copula }\end{array}$ \\
\hline Parameter & 1.9 & 1.9 & 5.7 & 0.7 & 0.7 & 1.8 & 1.7 & 5.1 & 0.7 & 0.7 & 2.7 & 3.0 & 9.8 & 0.9 & 0.9 \\
\hline Loglikelihood & 40.7 & 51.9 & 44.5 & 49.9 & 88.2 & 31.8 & 45.5 & 36.3 & 36.7 & 96 & 82.5 & 84.2 & $\begin{array}{c}86.0 \\
-\end{array}$ & 87.9 & 138.8 \\
\hline AIC & -79.5 & -101.9 & -87.1 & -95.8 & -168 & -61.7 & -89.1 & -70.6 & -69.4 & -184 & -163.1 & -166.3 & 169.9 & -171.7 & -269 \\
\hline KS & 0.2 & 0.1 & 0.2 & 0.3 & 0.6 & 0.4 & 0.1 & 0.4 & 0.9 & 0.6 & 0.1 & 0.1 & 0.2 & 0.1 & 0.6 \\
\hline Chisq & 0.0 & 0.2 & 0.2 & 0.1 & 0.3 & 0.2 & 0.1 & 0.1 & 0.0 & 0.5 & 0.0 & 0.0 & 0.0 & 0.0 & 0.2 \\
\hline CVM & 0.1 & 0.0 & 0.0 & 0.8 & 0.5 & 0.5 & 0.2 & 0.3 & 0.6 & 0.9 & 0.4 & 0.3 & 0.3 & 0.1 & 0.3 \\
\hline \multicolumn{16}{|l|}{ Lower sub basin } \\
\hline Parameter & 1.7 & 1.5 & 4.9 & 0.7 & 0.7 & 1.9 & 1.9 & 6.0 & 0.7 & 0.7 & 2.2 & 2.2 & 7.0 & 0.8 & 0.8 \\
\hline Loglikelihood & 30.9 & 39.7 & 33.1 & 42.9 & 87.5 & 41.4 & 52.0 & 46.5 & 44.0 & 106 & 61.2 & 61.8 & $\begin{array}{c}59.4 \\
-\end{array}$ & 64.6 & 137.5 \\
\hline AIC & -59.7 & -77.4 & -64.2 & -81.7 & -167 & -80.7 & -102.0 & -90.9 & -84.0 & -205 & -120.3 & -121.7 & 116.8 & -125.3 & -267 \\
\hline KS & 0.4 & 0.1 & 0.4 & 0.8 & 0.3 & 0.3 & 0.1 & 0.3 & 0.7 & 0.9 & 0.3 & 0.2 & 0.4 & 0.2 & 0.1 \\
\hline Chisq & 0.0 & 0.0 & 0.0 & 0.0 & 0.0 & 0.0 & 0.0 & 0.0 & 0.0 & 0.5 & 0.0 & 0.0 & 0.1 & 0.0 & 0.3 \\
\hline CVM & 0.0 & 0.0 & 0.0 & 1.0 & 1.0 & 0.3 & 0.1 & 0.2 & 0.2 & 0.6 & 0.2 & 0.1 & 0.1 & 0.1 & 0.5 \\
\hline
\end{tabular}

\subsection{Drought Characteristics Modelling using Pair-Copula Models}

In this section, the comparison between the trivariate copula analysis and the Pairwise

Copula Construction (PCC) of drought variables is carried out. The drought characteristics are

fitted using the PCC model based on the method explained in Section 3.5. Suitable vine 
structure between C-vine and D-vine models and the copula families must be selected for the dependent pair variables viz., peak - duration, duration - severity and severity - peak.

The dependency measures between pair variables of drought events are given in supplementary Table S7. This supporting document explains the stronger dependence between duration and severity. The next stronger dependency is observed between severity and peak. It can, hence, be concluded that the severity characteristic (S) must be present between duration (D) and peak (P). In this study, the D-vine structure is selected for further analysis. D-vine structure has more flexibility towards forming the pair copula rather than the C-vine structure because it creates a relationship of variables with a particular root variable that defines the key elements of the structure (Aas et al. 2009). Kendall's plots and Chi-plots of the pair variables peak - duration, duration - severity and severity - peak are given in the supplementary Figures (S1-S12) signifying positive dependencies between the pair variables. It can be concluded from the dependency measures and the Kendall's and Chi-plots of the pair variables, that duration severity showed the strongest dependency when compared to other pairs. The copula families for the pair variables are selected from various copulas. Clarke and Vuong tests are conducted to obtain the best fitted copula family.

In the first phase of parameter estimation method, the sequential parameters were estimated using the MLE method for these pairs of drought variables $\mathrm{D} / \mathrm{S}\left(\theta_{\mathrm{DS}}\right)$ and $\mathrm{S} / \mathrm{P}\left(\theta_{\mathrm{SP}}\right)$. Then for the second phase of parameter estimation, the respective $\mathrm{h}$ functions are computed between the pair variables $\mathrm{D} / \mathrm{S}$ and $\mathrm{S} / \mathrm{P}$. Then the parameter, $\theta_{\mathrm{DP} / \mathrm{S}}$ is estimated for drought variables $(\mathrm{D} / \mathrm{S}, \mathrm{S} / \mathrm{P})$. The copula families selected for the pair variables and the parameters estimated in the second phase $\left(\theta_{\mathrm{DP} / \mathrm{S}}\right)$ considering the best fitted copula for the Lower and Upper sub basins for different time scales (3-, 6-, 12-month) are given in Table 5.

Table 5. Pairwise Copula Construction (PCC) for NSPI and NRDI Drought Characteristics 


\begin{tabular}{|c|c|c|c|c|c|c|c|}
\hline $\begin{array}{c}\text { NSPI } \\
\text { Upper sub basin }\end{array}$ & Clarke & Vuong & AIC & \multicolumn{3}{|c|}{ Selected Bivariate Copula } & $\begin{array}{c}\text { Parameter } \\
\left(\theta_{D P / S}\right)\end{array}$ \\
\hline 3-month & 0.62 & 0.914 & -180.48 & Clayton & Gaussian & Clayton & 0.469 \\
\hline 6-month & 0.457 & 0.506 & -197.83 & Clayton & Frank & Gaussian & 0.429 \\
\hline 12-month & 0.0248 & 0.984 & -286.033 & Frank & Gumbel & Frank & 6.16 \\
\hline $\begin{array}{c}\text { NSPI } \\
\text { Lower sub basin }\end{array}$ & Clarke & Vuong & AIC & \multicolumn{3}{|c|}{ Selected Bivariate Copula } & $\begin{array}{c}\text { Parameter } \\
\left(\theta_{D P / S}\right)\end{array}$ \\
\hline 3-month & 0.0026 & 0.0619 & -169.575 & Clayton & Clayton & Gumbel & 0.244 \\
\hline 6-month & 0.62 & 0.692 & -205.71 & Clayton & Gaussian & Frank & 0.46 \\
\hline 12-month & 0.024 & 0.0607 & -273.98 & Gaussian & Gumbel & Gaussian & 0.623 \\
\hline $\begin{array}{c}\text { NRDI } \\
\text { Upper sub basin }\end{array}$ & Clarke & Vuong & AIC & \multicolumn{3}{|c|}{ Selected Bivariate Copula } & $\begin{array}{c}\text { Parameter } \\
\left(\theta_{D P / S}\right)\end{array}$ \\
\hline 3-month & 0.703 & 0.6874 & $\begin{array}{l}-199.82 \\
\end{array}$ & Clayton & Frank & Gaussian & 0.4855 \\
\hline 6-month & 0.526 & 0.358 & -168.57 & Gaussian & Gaussian & Clayton & 0.291 \\
\hline 12-month & 0.511 & 0.556 & -140.8 & Gumbel & Gumbel & Gumbel & 1.79 \\
\hline $\begin{array}{c}\text { NRDI } \\
\text { Lower sub basin }\end{array}$ & Clarke & Vuong & AIC & \multicolumn{3}{|c|}{ Selected Bivariate Copula } & $\begin{array}{c}\text { Parameter } \\
\left(\theta_{D P / S}\right)\end{array}$ \\
\hline 3-month & 0.055 & 0.009 & -224.66 & Gaussian & Frank & Clayton & 0.362 \\
\hline 6-month & 1 & 0.459 & -171.19 & Clayton & Clayton & Gaussian & 0.338 \\
\hline 12-month & 1 & 0.418 & -147.97 & Gumbel & Gumbel & Gumbel & 1.694 \\
\hline
\end{tabular}

In the second phase of parameter estimation, the copula is selected from the first phase

of copula families fitted for estimation of the sequential parameter. For example, in case of the generated drought characteristics from 3- month NRDI, Gaussian copula is selected for estimation of the second phase of the parameter. Finally, this PCC model, accounting for the drought variables, is compared with the derived trivariate copula using the AIC criteria. It can be observed from Table 6 that the AIC of the trivariate model showed higher AIC value compared to PCC based model. This shows that the PCC model is more suitable than the trivariate copula model for modelling the multivariate approach of drought variables. It can, hence, be justified that the PCC model can flexibly model the drought characteristics by transforming the bivariate model to a higher dimensional model.

Table 6 Comparison between trivariate Student's t copula and PCC model

\begin{tabular}{|c|c|c|}
\hline Upper sub basin & Student's t copula & PCC \\
\hline 3-month & -168.3 & -180.5 \\
\hline 6-month & -184.2 & -197.8 \\
\hline 12-month & -269.6 & -286 \\
\hline Lower sub basin & Student's t copula & PCC \\
\hline 3-month & -167 & -169.6 \\
\hline 6-month & -205.2 & -205.7 \\
\hline 12-month & -267.1 & -273.98 \\
\hline Upper sub basin & Student's t copula & PCC \\
\hline 3-month & -187.05 & -199.8 \\
\hline
\end{tabular}




\begin{tabular}{|c|c|c|}
\hline 6-month & -154.646 & -168.57 \\
\hline 12-month & -133.197 & -140.8 \\
\hline Lower sub basin & Student's t copula & PCC \\
\hline 3-month & -184.635 & -224.66 \\
\hline 6-month & -165.9 & -171.19 \\
\hline 12-month & -129.371 & -147.97 \\
\hline
\end{tabular}

\section{Return Period analysis of Drought variables}

The multivariate drought frequency analysis is beneficial for representing complex characteristics of drought events on a river basin scale. Various studies have used trivariate copula analysis for understanding the multivariate pattern of drought characteristics (Ganguli and Reddy 2013, Saghafian and Mehdikhani, 2014). In this present study, the PCC model is also used for analysing the drought return period. This kind of study is beneficial for the qualitative planning and management, development of the safety measures and drought hazard mitigation strategies.

The drought frequency analysis can be related to the occurrence of extreme events and their probability distributions. Here values of peak, duration and severity that exceeds their truncation level ( $\mathrm{S} \geq \mathrm{s}, \mathrm{D} \geq \mathrm{d}, \mathrm{P} \geq \mathrm{p}$ ) are considered for analysing the multivariate drought frequency. The joint return period analysis is carried out by using the two probability cases i.e. (i) primary return period "AND" and secondary return period "OR" for the drought variable using the approach suggested by Salvadori and Michele (2004). For annual drought analysis the mathematical expression for return period considering the "AND" and "OR" case is represented in Eq. 25 and Eq. 26

$$
\begin{aligned}
T_{(S D P)}^{A N D} & =\frac{\varepsilon}{P(S \geq s, D \geq d, P \geq p)}=\frac{\varepsilon}{1-F_{S}(s)-F_{D}(d)-F_{P}(p)+F_{S, D}(s, d)+F_{D, P}(d, p)+F_{P, S}(p, s)-F_{S, D}, P(s, d, p)} \\
& =\frac{\varepsilon}{1-F_{S}(s)-F_{D}(d)-F_{P}(p)+C\left(u_{1}, u_{2}\right)+C\left(u_{2}, u_{3}\right)+C\left(u_{3}, u_{1}\right)-C\left(u_{1}, u_{2}, u_{3}\right)} \\
T_{S D P}^{O R} & =\frac{\varepsilon}{P(S \geq s, D \geq d, P \geq P)} \\
& =\frac{\varepsilon}{1-P(S \geq s, D \geq d, P \geq P)}=\frac{\varepsilon}{1-F_{S, D, P}(s, d, p)}=\frac{\varepsilon}{1-C\left(u_{1}, u_{2}, u_{3}\right)}
\end{aligned}
$$


Supplementary Tables (S8-S11) show the joint return periods ("AND" and "OR" cases) obtained from the trivariate copula and PCC models using the drought characteristics for NSPI and NRDI for 3-, 6- and 12- month time scale. Here $\mathrm{T}_{(\mathrm{SDP})}^{\mathrm{AND}} \mathrm{TC}$ and $\mathrm{T}_{(\mathrm{SDP})}^{\mathrm{AND}} \mathrm{PCC}$ represent as the joint return periods for trivariate Student's t copula and PCC model respectively. Similarly, the joint return period of "OR" case can be denoted as $\mathrm{T}_{\mathrm{SDP}}^{\mathrm{OR}} \mathrm{TC}$ and $\mathrm{T}_{(\mathrm{SDP})}^{\mathrm{OR}} \mathrm{PCC}$ for trivariate Student's t copula and PCC models respectively. The "OR” joint return periods are less compared to "AND” return periods in both trivariate Student's t copula and PCC models. So it can be concluded that the frequency of drought is more in the "OR" case when compared to the "AND" case.

\section{Conclusions}

In the present study, two non-stationary drought indices (NSPI and NRDI) have been developed using the GAMLSS algorithm incorporating the global scale climate indices. The non-stationary drought indices are defined by the time varying location parameter associated with the external covariates (SST, SOI, MEI, and IOD). The preferred climate indices here are arranged in different lag values for several months (0-12 lags). The strong links between rainfall and evapotranspiration variability with global scale climate indices gives a clear picture of non-stationarity drought assessment. In this study, the concept of non-stationarity is employed by aggregating the precipitation and initial value series with the large scale climate indices with lag time of $0-12$ months. Hence, it can be concluded that the non-stationary meteorological droughts considering the global scale climate indices are capable of capturing the drought events. Stationary drought indices are not efficient in capturing the drought frequency in extreme condition. The variations in precipitation are directly dependent on the global scale climate indices. In a country like India, both precipitation and evapotranspiration play an important in the occurrence of drought events. Therefore, this study considers both 
precipitation and evapotranspiration based non-stationary drought indices (NSPI and NRDI) to identify more complex aspect of drought occurrence.

The probabilistic estimation of drought characteristics must be carried out to estimate the recurrence intervals of droughts. In this study, the trivariate Student's t copula and the PCC copula model are used to assess the drought recurrence intervals. The trivariate Student's t copula and PCC model are compared based on their respective AIC values. The standard multivariate copulas are not flexible enough to model the higher dimensional copula for assessment of extreme events. These drawbacks of multivariate copulas can be removed using D-vine copula models. So a D-vine PCC model is also used in this study to find the primary and secondary drought return periods. The conclusions derived in the present study are:

1. The non-stationary models (NSPI and NRDI) performed better compared to the stationary models (SPI and RDI) as the AIC values are lower in case of non-stationary models. In case of the Upper Godavari sub basin, NSPI and NRDI showed a significant influence at various lags for 3-, 6- and 12- month time scales. In case of the Lower Godavari sub basin, SOI, MEI and SST are the most influential large oscillations for both NSPI and NRDI at different time scales.

2. The non-stationary and stationary models showed variations in their time signals. This is because of the fitted non- stationary Gamma and Log-normal distributions for the computation of NSPI and NRDI respectively integrating the large scale climate indices. The box plots between drought variables revealed that the drought properties significantly varied under stationary and non-stationary conditions in the Lower and Upper sub basins for 12-month time scale when compared to 3- and 6-month time scale.

3. The "AND" and "OR' joint return periods for PCC models are higher compared to those obtained from the trivariate Student's t copula model for both the non-stationary models 
(NSPI and NRDI). So it can be understood that the drought frequencies for PCC model is higher as compared to the trivariate Student's t copula.

4. After analysing the trivariate and PCC models, the return periods showed variations between AND and OR return periods for both NSPI and NRDI in different time scales. The variations of return periods between trivariate Student's t copula and PCC model are significant in case of 12-month time scale for both the non-stationary drought events. Conclusion derived that the primary and secondary return periods predicted by PCC model are more accurate compared to trivariate Student's t-copula model as PCC model performed better than the trivariate Student's t copula.

\section{Declarations \\ Funding (NA)}

Conflicts of interest/Competing interests (NA)

Availability of data and material (Available)

Code availability (Available) 


\section{References}

Aas K, Czado KC, Frigessi A, Bakken H (2009) Pair-copula constructions of multiple dependence. Insur Math Econ 44:182-198.

Bazrafshan J, Hejabi S (2018) A non-stationary reconnaissance drought index (NRDI) for drought monitoring in a changing climate. Water Resour Manag 32(8):2611-2624. https://doi.org/10.1007/s11269-018-1947-z.

Bedford T, Cooke RM (2002) Vines: A new graphical model for dependent random variables. Ann Stat 1031-1068. https://www.jstor.org/stable/1558694.

Bedford T, Cooke RM (2001) Probability density decomposition for conditionally dependent random variables modelled by vines. Ann Math Artif Intell 32:245-268.

Bhalme HN, Jadhav SK (1984) The Southern Oscillation and its relation to the monsoon rainfall. J Clim 4(5):509-520. https://doi.org/10.1002/joc.3370040506.

Brechmann EC, Schepsmeier (2013) Modeling dependence with C- and D-vine copulas: the R package CDVine. J Stat Softw 52 (3): 1-27. https://www.jstatsoft.org/.

Clarke KA (2007) A simple distribution-free test for non-nested model selection. Polit Anal 15 (3):347-363.

Daneshkhah A, Remesan R, Chatrabgoun, O, Holman, IP (2016) Probabilistic modeling of flood characterizations with parametric and minimum information pair-copula model. $\mathbf{J}$ Hydrol 540:469-487. https://dx.doi.org/10.1016/j.jhydrol.2016.06.044.

Das J, Jha S, Goyal MK (2020) Non-stationary and copula-based approach to assess the drought characteristics encompassing climate indices over the Himalayan states in India. J Hydrol 580:24356. https://doi.org/10.1016/j.jhydrol.2019.124356.

Debele SE, Strupczewski WG, Bogdanowicz E (2017) A comparison of three approaches to non-stationary flood frequency analysis. Acta Geophys 65(4):863-883. DOI 10.1007/s11600017-0071-4.

Dutta D, Kundu A, Patel NR, Saha SK, Siddiqui AR (2015) Assessment of agricultural drought in Rajasthan (India) using remote sensing derived Vegetation Condition Index (VCI) and Standardized Precipitation Index (SPI). The Egyptian Journal of Remote Sensing and Space Science 18(1):53-63. https://dx.doi.org/10.1016/j.ejrs.2015.03.006.

Ganguli P, Reddy MJ (2012) Risk Assessment of Droughts in Gujarat Using Bivariate Copulas. Water Resour Manag 26:3301-3327. https://doi.org/10.1007/s11269-012-0073-6.

Ganguli P, Reddy MJ (2013) Analysis of ENSO-based climate variability in modulating drought risks over western Rajasthan in India. J Earth Syst Sci 122:253-269. https://doi.org/10.1007/s12040-012-0247-x.

Genest C, Favre AC (2007) Everything you always wanted to know about copula modelling but were afraid to ask. J Hydrol Eng 12(4):347-368. https://doi:10.1029/2006WR005275. 
Genest C, Favre AC, Béliveau J, Jacques C (2007) Metaelliptical copulas and their use in frequency analysis of multivariate hydrological data. Water Resour Res 43(9): https://doi:10.1029/2006WR005275.

Gräler B, van den Berg M, Vandenberghe S, Petroselli A, Grimaldi S, De Baets B, Verhoest N (2013) Multivariate return periods in hydrology: a critical and practical review focusing on synthetic design hydrograph estimation. Hydrol Earth Syst Sci 17(4), 1281-1296. https:// doi: 10.5194/hess-17-1281-2013.

Grimaldi S, Serinaldi F (2006) Asymmetric copula in multivariate flood frequency analysis. Adv Water $\quad$ Resour 29(8):1155-1167. https://doi.org/10.1016/j.advwatres.2005.09.005.

Hao Z, AghaKouchak A (2013) Multivariate standardized drought index: a parametric multiindex model. Adv Water Resour 57:12-18. https://doi.org/10.1016/j.advwatres.2013.03.009.

Harris I, Osborn TJ, Jones P, Lister D (2020) Version 4 of the CRU TS monthly high-resolution gridded multivariate climate dataset. Sci. Data 7(1):1-18.

Kahya E, Dracup JA (1993) US streamflow patterns in relation to the El Niño/Southern Oscillation. Water Resour Res 29(8):2491-2503.

Kao SC, Govindaraju RS (2010) A copula-based joint deficit index for droughts. J Hydrol 380 (1-2):121-134.https:// doi:10.1016/j.jhydrol.2009.10.029

Kendall MG (1955) Rank correlation methods. Hafner Publishing Co., Oxford, England.

Keyantash JA, Dracup JA (2004) An aggregate drought index: assessing drought severity based on fluctuations in the hydrologic cycle and surface water storage. Wat Resour Res 40 (9): https:// doi:10.1029/2003WR002610, 2004.

Krishnamurthy V, Kirtman BP (2003) Variability of the Indian Ocean: Relation to monsoon and ENSO. Q J R Meteorolog Soc 129(590):1623-1646. https:// doi: 10.1256/qj.01.166.

Kurowicka D, Cooke R (2006) Uncertainty Analysis with High Dimensional Dependence Modeling. John Wiley.

Lawal S, Lennard C, Jack C, Wolski P, Hewitson B, Abiodun B (2019) The observed and model-simulated response of southern African vegetation to drought. Agr Forest Meteorol 279(12):1-18. https://doi.org/10.1016/j.agrformet.2019.107698.

Mckee TB, Doesken NJ, Kleist J (1993) The relationship of drought frequency and duration to time scale. In: Proceedings of the Eighth Conference on Applied Climatology. Am Meteorol Soc pp. $179-184$.

Milly PCD, Betancourt J, Falkenmark M, Hirsch RM, Kundzewicz ZW, Lettenmaier DP, Stouffer RJ (2008) Stationarity is dead: Whither water management?. Earth. 4:20.

Mishra AK, Singh VP (2010) A review of drought concepts. J Hydrol 391:202-216. https://doi.org/10.1016/j.jhydrol.2010.07.012.

Mishra AK, Singh VP, Desai VR (2009) Drought characterization: a probabilistic approach. Stoch. Environ Res Risk Assess 23:41-55. https://doi.org/10.1007/s00477-007-0194-2. 
Mishra V, Aadhar S, Asoka A, Pai S, Kumar R (2016) On the frequency of the 2015 monsoon season drought in the Indo-Gangetic Plain. Geophys Res Lett 43:12102-12112. https://doi.org/10.1002/2016GL071407.

Narasimhan B, Srinivasan R (2005) Development and evaluation of Soil Moisture Deficit Index (SMDI) and Evapotranspiration Deficit Index (ETDI) for agricultural drought monitoring. Agric For Meteorol 133(1-4):69-88. https://doi:10.1016/j.agrformet.2005.07.012.

Nelsen RB (2006) An Introduction to Copulas. Springer, New York.

Oguntunde PG, Abiodun BJ, Lischeid G (2017) Impacts of climate change on hydrometeorological drought over the Volta Basin, West Africa Glob Planet Change 155:121-132. https://doi.org/10.1016/j.gloplacha.2017.07.003

Osorio JG, Galiano SG (2012) Non-stationary analysis of dry spells in monsoon season of Senegal River Basin using data from Regional Climate Models (RCMs). J Hydrol 450:82-92. https://doi.org/10.1016/j.jhydrol.2012.05.029.

Palmer WC (1998) Keeping track of crop moisture conditions, nationwide: the new crop moisture index. Taylor \&Francis. 156-161. https://doi.org/10.1080/00431672.1968.9932814

Pervez MS, Henebry GM (2015) Spatial and seasonal responses of precipitation in the Ganges and Brahmaputra river basins to ENSO and Indian Ocean dipole modes: implications for flooding and drought. Nat. Hazards Earth Syst Sc. 15(1):147. https://doi:10.5194/nhess-15$147-2015$.

Pokhrel S, Chaudhari HS, Saha SK, Dhakate A, Yadav RK, Salunke K, Rao SA (2012) ENSO, IOD and Indian Summer Monsoon in NCEP climate forecast system. Clim Dyn 39(9-10): 2143-2165.https:// DOI 10.1007/s00382-012-1349-5.

Prabhakar SVRK, Shaw R (2008) Climate change adaptation implications for drought risk mitigation: a perspective for India. Clim. Change. 88(2), 113-130. https:// DOI 10.1007/s10584-007-9330-8.

Rashid MM, Beecham, S., 2019. Development of a non-stationary Standardized Precipitation Index and its application to a South Australian climate. Sci. Total Environ. 657, 882-892. https://doi.org/10.1016/j.scitotenv.2018.12.052.

Rigby RA, Stasinopoulos DM (2005) Generalized additive models for location, scale and shape. J R Stat Soc Ser C Appl Stat 54:507-554. https://doi.org/10.1177/0962280212473302.

Russo S, Dosio A, Sterl A, Barbosa P, Vogt J (2013) Projection of occurrence of extreme drywet years and seasons in Europe with stationary and nonstationary Standardized Precipitation Indices. J Geophys Res Atmos 118:7628-7639. https://doi:10.1002/jgrd.50571, 2013.

Saghafian B, Mehdikhani H (2014) Drought characterization using a new copula-based trivariate approach. Nat Hazards 72(3):1391-1407. https://DOI 10.1007/s11069-013-0921-6.

Sahai AK, Grimm AM, Satyan V, Pant GB (2003) Long-lead prediction of Indian summer monsoon rainfall from global SST evolution. Clim Dyn 20(7-8):855-863. https://DOI 10.1007/s00382-003-0306-8. 
Saji NH, Goswami BN, Vinayachandran PN, Yamagata T (1999) A dipole mode in the tropical Indian Ocean. Nature 401:360-363. https://doi.org/10.1038/43854.

Salvadori G, De Michele C (2004) Frequency analysis via copulas: Theoretical aspects and applications to hydrological events. Water Resour Res 40(12). https://doi:10.1029/2004WR003133.

Salvadori G, Durante F, De Michele C (2011) On the return period and design in a multivariate framework. https://doi:10.5194/hess-15-3293-2011.

Schirmacher D, Schirmacher E (2008) Multivariate dependence modelling using paircopulas pp. 14-16.

Shafer BA, Dezman LE (1982) Development of Surface water supply index (SWSI) to assess the severity of drought condition in snowpack runoff areas. Proceeding of the western snow conference.

Shukla S, Wood AW (2008) Use of a standardized runoff index for characterizing hydrologic drought. Geophys Res Lett 35, L02405. https://doi.org/10.1029/2007GL032487.

Sklar M (1959) Fonctions de repartition an dimensions et leurs marges. Publ inst statist Univ Paris. 8:229-231.

Song SB, Kang Y (2011) Pair-copula decomposition constructions for multivariate hydrological drought frequency analysis. In 2011 International Symposium on Water Resource and Environmental Protection. 4:2635-2638.

Stasinopoulos M, Rigby RA (2007) Generalized Additive Models for Location Scale and Shape (GAMLSS) in R J Stat Softw 223:1-46. https://doi.org/10.1111/j.1467-9876.2005.00510.x.

Svoboda M, LeComte D, Hayes M, Heim R, Gleason K, Angel J, Rippey B, Tinker R, Palecki M, Stooksbury D, Miskus D, Stephens S (2002) The drought monitor Bull Am Meteorol Soc 83:1181-1190.

Tamaddun KA, Kalra A, Bernardez M, Ahmad S (2019) Effects of ENSO on temperature, precipitation, and potential evapotranspiration of North India's monsoon: An analysis of trend and entropy. Water. 11(2):189.https:// doi:10.3390/w11020189.

Trenberth KE, Dai A, Van Der Schrier G, Jones PD, Barichivich J, Briffa KR, Sheffield J (2014) Global warming and changes in drought. Nat Clim Change 4(1):17-22.https:// DOI: 10.1038/NCLIMATE2067.

Tsakiris G, Pangalou D, Vangelis H (2007) Regional drought assessment based on the Reconnaissance Drought Index (RDI). Water Resour Manag 21(5):821-833.

Tsakiris G, Vangelis HJEW (2005) Establishing a drought index incorporating evapotranspiration. European water 9(10):3-11.

Vicente-Serrano SM, Beguería S, Lopez-Moreno JI (2010) A multiscalar drought index sensitive to global warming: the standardized precipitation evapotranspiration index. J Clim 23(7):1696-1718. https://doi.org/10.1175/2009JCLI2909.1. 
Villarini G, Smith JA, Serinaldi F, Bales J, Bates PD, Krajewski WF (2009) Flood frequency analysis for non-stationary annual peak records in an urban drainage basin. Adv Water Resour 32(8):1255-1266. https://doi.org/10.1016/j.advwatres.2009.05.003.

Vuong QH (1989) Likelihood ratio tests for model selection and non-nested hypotheses. Econometrica 57 (2):307-333. https://www.jstor.org/stable/1912557.

Wang Y, Li J, Feng P, Hu R (2015) A Time-Dependent Drought Index for Non-Stationary Precipitation Series. Water Resour Manag 29:5631-5647. https:// DOI 10.1007/s11269-015$1138-0$

Yevjevich V (1967) An objective approach to definitions and investigations of continental hydrologic drought. Hydrology Paper no. 23. Fort Collins, Colorado.

Zarch MAA, Sivakumar B, Sharma A (2015) Droughts in a warming climate: A global assessment of Standardized precipitation index (SPI) and Reconnaissance drought index (RDI). J Hydrol 52:183-195. https://doi.org/10.1016/j.jhydrol.2014.09.071.

Zhang Q, Xiao M, Singh VP (2015) Uncertainty evaluation of copula analysis of hydrological droughts in the East River basin, China. Glob Planet Change, 129:1-9. 10.1016/j.gloplacha.2015.03.001 


\section{Figures}
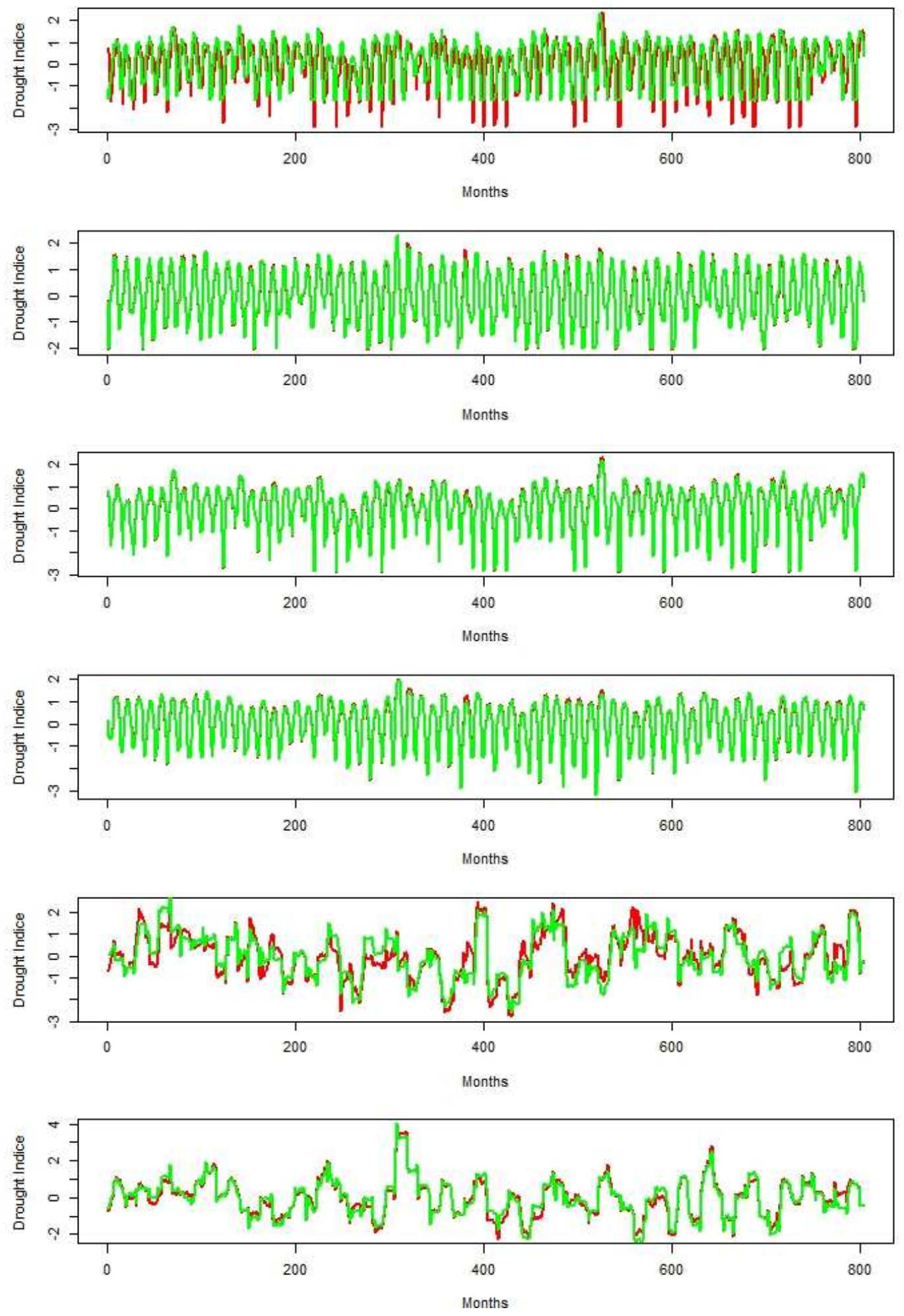

Figure 1

The NSPI and SSPI drought signals during 1951-2017 for 3-, 6- and 12-month time scales: first time series shows 3-month time scale for Upper Godavari sub basin; second time series shows 3-month time scale for Lower Godavari sub basin; third time series shows 6-month time scale for Upper Godavari sub basin; 
fourth time series shows 6-month time scale for Lower Godavari sub basin; fifth time series shows 12month time scale for Upper Godavari sub basin; sixth time series shows 12-month time scale for Lower Godavari sub basin.
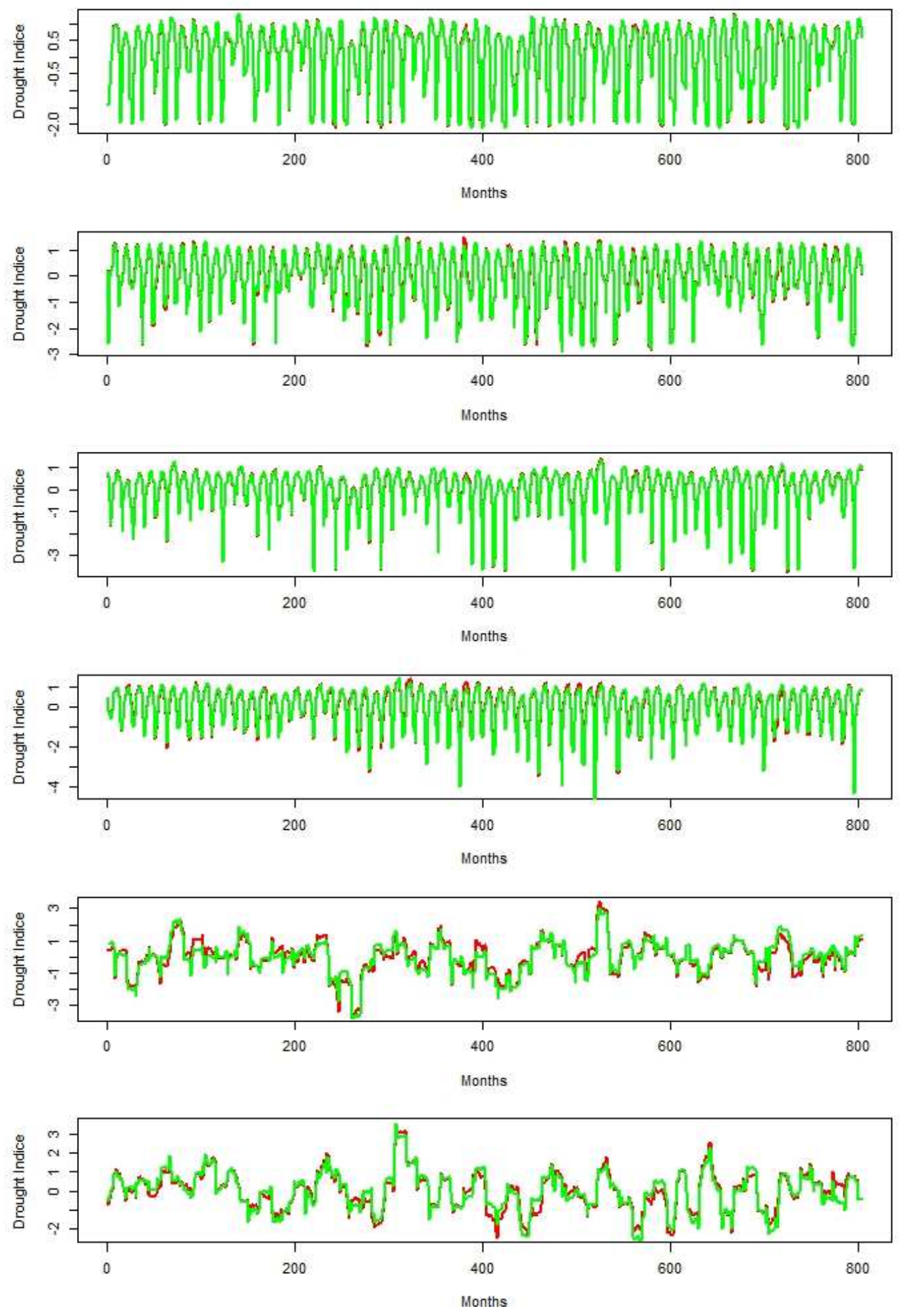

Figure 2

The NRDI and SRDI drought signals during 1951-2017 for 3-, 6- and 12-month time scales: first time series shows 3-month time scale for Upper Godavari sub basin; second time series shows 3-month time 
scale for Lower Godavari sub basin; third time series shows 6-month time scale for Upper Godavari sub basin; fourth time series shows 6-month time scale for Lower Godavari sub basin; fifth time series shows 12-month time scale for Upper Godavari sub basin; sixth time series shows 12-month time scale for Lower Godavari sub basin
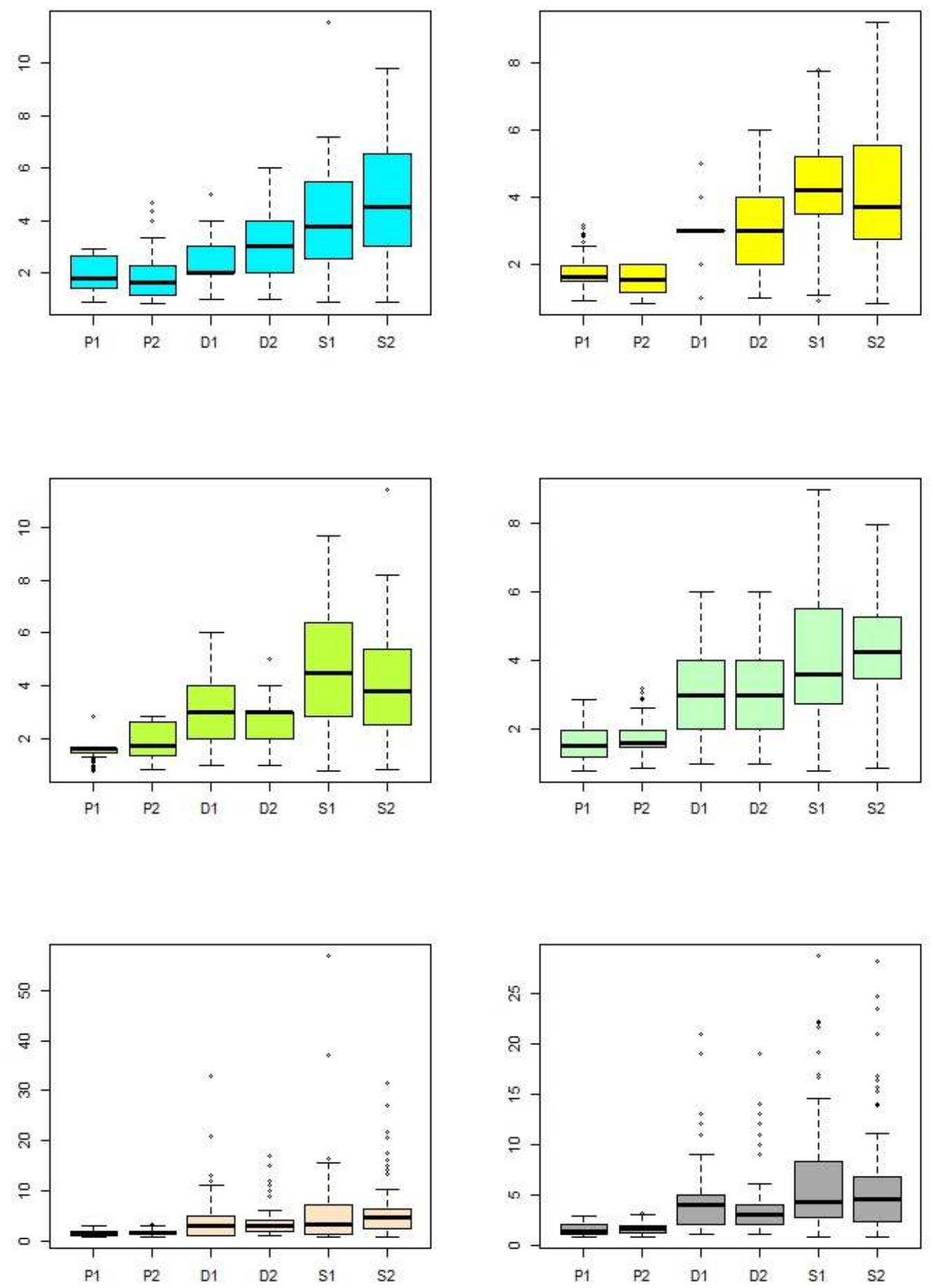

Figure 3 
The comparison using box plots for drought variables (peak, duration and severity) for stationary and non-stationary drought signals: first row shows comparison of drought variables for NSPI and SSPI for 3month time scale for Upper sub basin and Lower sub basin respectively; Second row show comparison of drought variables for NSPI and SSPI for 6-month time scale for Upper sub basin and Lower sub basin respectively; third row show comparison of drought variables for NSPI and SSPI for 12-month time scale for Upper sub basin and Lower sub basin respectively.
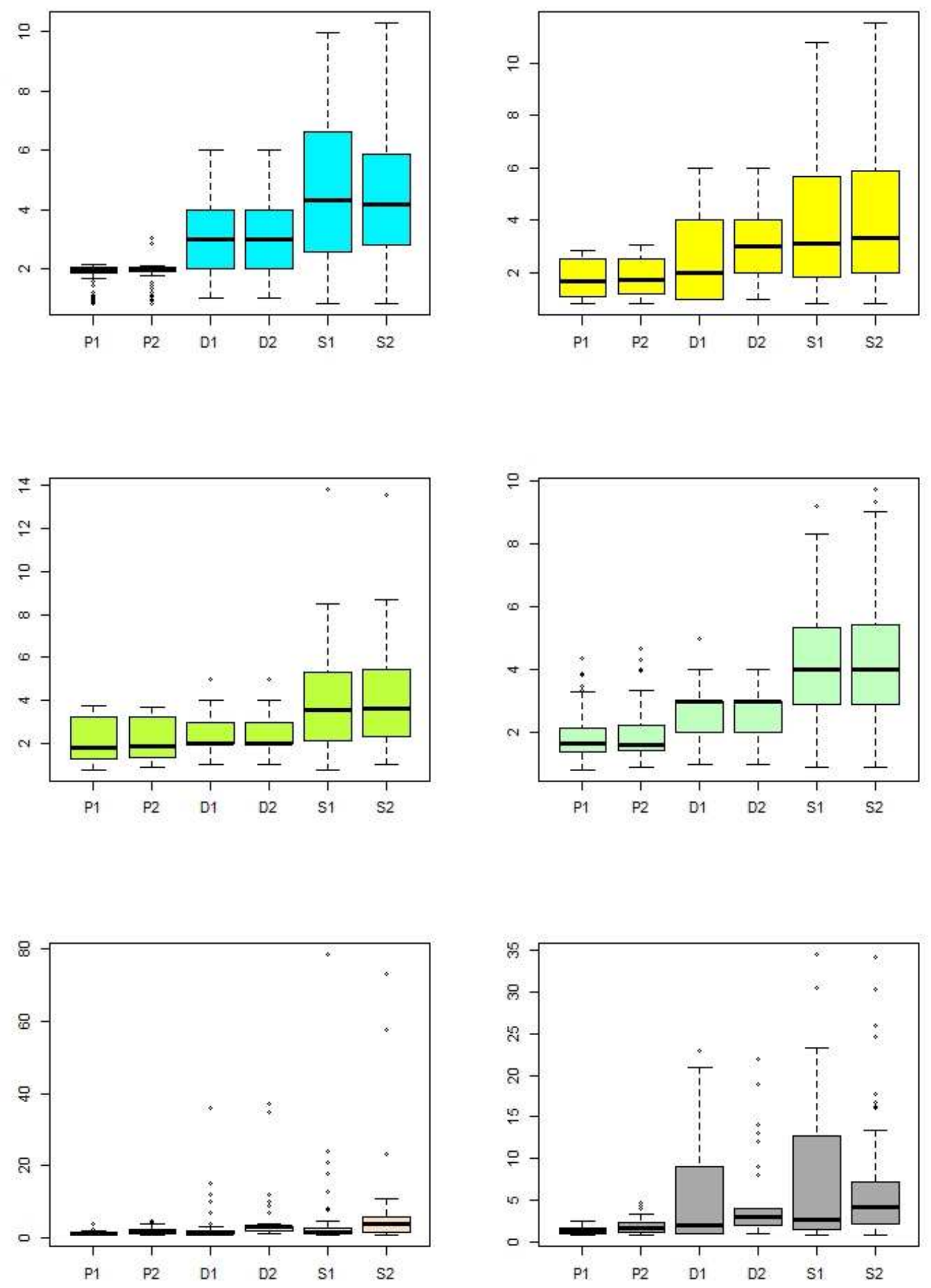

Figure 4 
The comparison using box plots for drought variables (peak, duration and severity) for stationary and non-stationary drought signals: first row shows comparison of drought variables for NRPI and SRDI for 3month time scale for Upper sub basin and Lower sub basin respectively; Second row show comparison of drought variables for NRDI and SRDI for 6-month time scale for Upper sub basin and Lower sub basin respectively; third row show comparison of drought variables for NRDI and SRDI for 12-month time scale for Upper sub basin and Lower sub basin respectively.

\section{Supplementary Files}

This is a list of supplementary files associated with this preprint. Click to download.

- NSPINRDIWRMsupplementary27MARCH.docx 